\title{
Modeling $\mathrm{pCO}_{2}$ in the Upper Ocean: a Review of Relevant Physical, Chemical, and Biological Processes
}

Prepared by:

David Archer

School of Oceanography, WB-10

University of Washington

Seattle, WA 98195

Under Contract No. DE-AC02-76RL01830 


\section{Abstract}

The $\mathrm{pCO}_{2}$ of the surface ocean is controlled by a combination of physical, chemical, and biological processes. Modeling surface ocean $\mathrm{pCO}_{2}$ is analogous to modeling sea surface temperature (SST), in that sea surface $\mathrm{pCO}_{2}$ is affected by fluxes across the air-sea interface and by exchange with deeper water. However, $\mathrm{pCO}_{2}$ is also affected by chemical and biological processes which have no analog in SST. Seawater $\mathrm{pCO}_{2}$ is buffered by $\mathrm{pH}$ equilibritm reactions between the species $\mathrm{CO}_{2}, \mathrm{HCO}_{3}{ }^{-}$, and $\mathrm{CO}_{3}=$. This effect provides an effective reservoir for $\mathrm{CO}_{2}$ in seawater that is 10 times larger than it would be for an unbuffered gas. The equilibrium between dissolved and atmospheric $\mathrm{CO}_{2}$ is sensitive to temperature, tending to higher $\mathrm{pCO}_{2}$ in warmer water.

Brological export of carbon as sinking particles maintains a gradient of $\mathrm{pCO}_{2}$, with lower values near the surface (this processes is called the "biological pump"). In most of the ocean, biological activity removes all of the available nutrients from the surface water; that is, the rate of carbon export in these locations is limited by the rate of nutrient supply to the euphotic zone. However, in much of the high-latitude oceans, primary production does not deplete the euphotic zone of nutrients, a fact to which the atmospheric $\mathrm{pCO}_{2}$ is extraordinarily sensitive. Understanding the limits to phytoplankton growth in the high latitudes, and how these limits might change under different climatic regimes, is essential to prediction of future ocean uptake of fossil fuel $\mathrm{CO}_{2}$.

Because many of the processes controlling sea suface $\mathrm{pCO}_{2}$ are driven by mixing in the upper ocean, fluctuations in the depth of the mixed layer are of primiary importance to modeling sea surface $\mathrm{pCO}_{2}$. The depth of the mixed layer can be predicted using a numerical model of the upper ocean. Fluxes of heat, momentum, and dissolved gases provide the boundary conditions for such a model. A major limitation on the precision of calculated heat fluxes is the effect of clouds on the atrospheric radiative 
heat fluxes.

Three families of mixed layer models have been developed, and although the physical mechanisms by which mixing occurs differ among the model groups, all are successful at predicting the observed ocean mixed layer depth. The "integrated turbulent kinetic energy" (TKE) models construct a budget for surface ocean TKE, using the wind stress as source and dissipation as sink for TKE. Excess kinetic energy is converted to potential energy by mixing denser water up into the surface mixed layer. The "shear instability" models maintain profiles of current velocity resulting from the wind stress; when the current shear becomes too large relative to density stratification, the model mixes (entrains) deep water into the surface layer. "Turbulence closure" models are the most general and the most complicated of the three types, and are based on laboratory studies of fluid turbulence. This paper explores behavioral distinctions between the three types of models, and summarizes previously published comparisons of the generality, accuracy, and computational requirements of the three models. The application of mixed layer models to treatment of sea ice is also reviewed.

Simulation of the upper ocean on a global scale is limited by finite computation resources and by imperfect meteorological forcing data. The air-sea heat fluxes can either be calculated as described above or imposed using an "SST restoring" strategy which pushes the model SST toward observations within some relaxation time constant. Simulation of free convection driven by surface cooling, particularly deep convection in high-latitude winter, is essential to modeling formation of cleep water and is therefore an integral part of virtually all circulation models. Convection driven by the wind (forced convection) requires higher spatial resolution and more detailed meteorological forcing data. One strategy for reducing overhead associated with the mixed layer is to "embed" the mixed layer into a surface box of variable thickness, within a deeper surface box. All three mixed layer model types have beer incorporated into global-scale simulations. 


\section{Table of Contents}

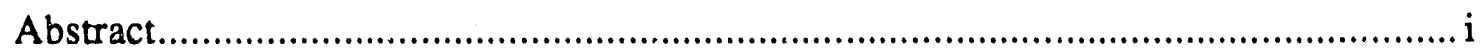

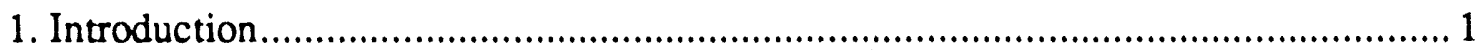

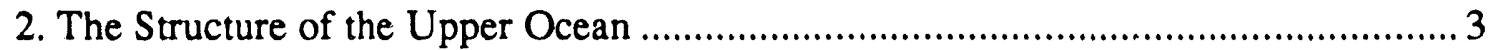

3. Biological and Chemical Processes in the Upper Ocean....................................... 5

3.1 A Summary of Carbonate Buffer System Chemistry ............................... 5

3.1.1 Aqueous Chemistry ........................................................ 6

3.1.2 Gas Equilibrium Chemistry ............................................... 8

3.2 The Biological Pump and Nutrient Cycling .......................................... 9

3.3 Limits to Primary Production........................................................... 14

3.4 Recycling Efficiency in the Euphotic Zone .......................................... 16

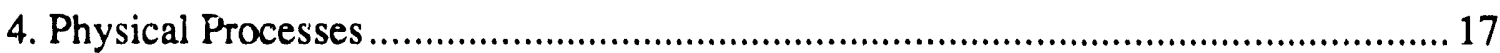

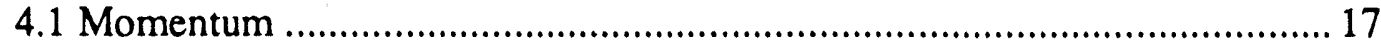

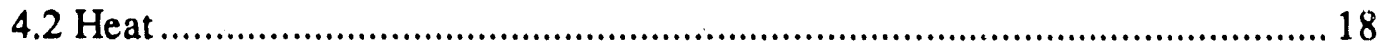

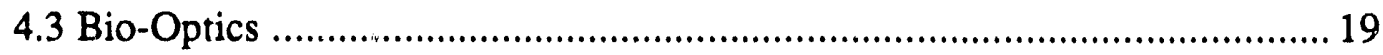

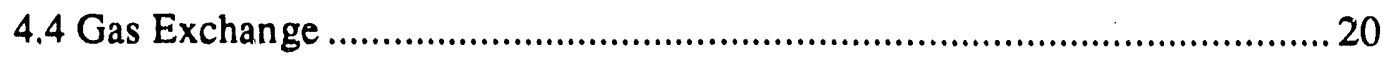

5. Overview of Mixed Layer Models ................................................................... 21

5.1 Integrated TKE, or "Bulk", Models ....................................................... 21

5.2 Shear Instability Models ................................................................ 23

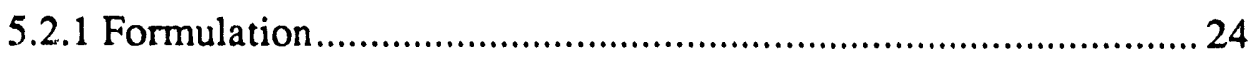

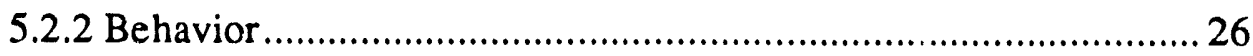

5.3 Turbulence Closure Models ............................................................... 27

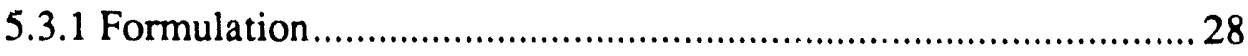

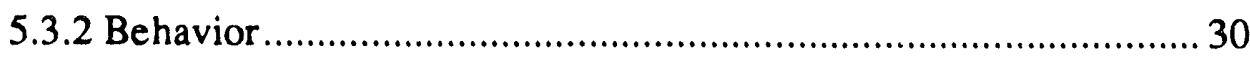

5.4 Mixed Layer Model Comparison......................................................... 31

5.4.1 The Stability of Empirical Parameters .................................... 32

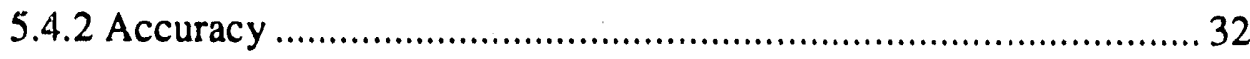

5.4.3 Computational Efficiency .................................................. 33

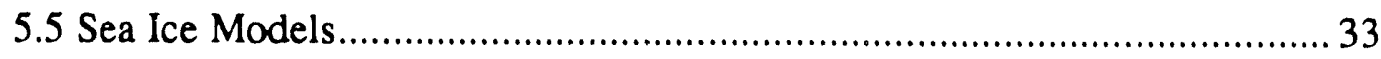

5.5.1 Ice-Only Models............................................................. 34

5.5.1.1 Thermodynamic Models .......................................... 34

5.5.1.2 Marginal Ice Zone Models ....................................... 34

5.5.2 Coupled Sea Ice / Mixed Layer Dynamics Models...................... 35

6. The Mixed Layer in Ocean Circulation Models. ................................................... 37 


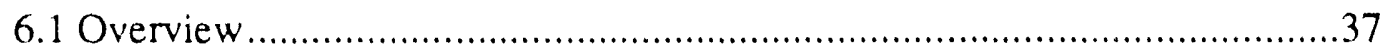

6.1.1 Calculated Heat Fluxes vs. SST-Restoring Models........................38

6.1.2 Simulating Free and Forced Convection.....................................38

6.1.3 High Spatial Resolution vs. Embedded Models.............................38

6.2 Examples of the Mixed Layer in Circulation Mc dels ....................................39

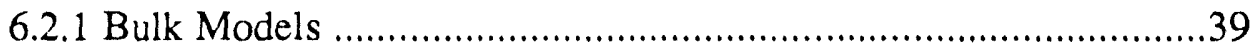

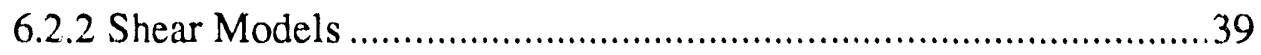

6.2.3 Turbulence Closure Models .......................................................40

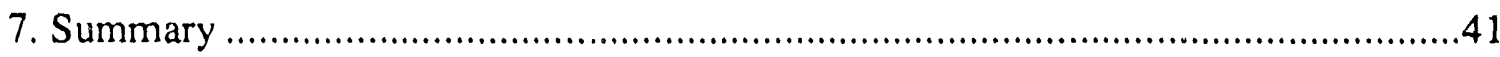

8. Acknowledgements

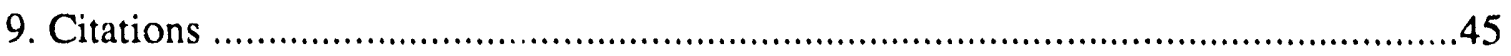

Appendix A. Annotated Bibliography of Mixed Layer Models. ...............................53

A.1 Bulk Wind-Stress Driven Models. ...........................................................53

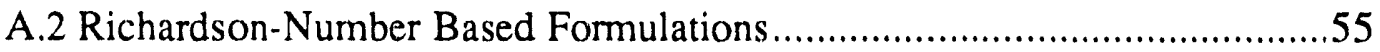

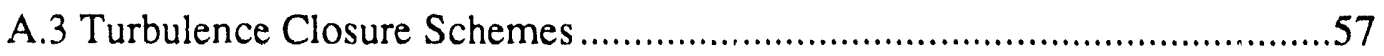

Appendix B. Annotated Bibliography of General Circulation Models .........................59

B.1 Models descended from Bryan and Cox (GFDL) ……….......................59

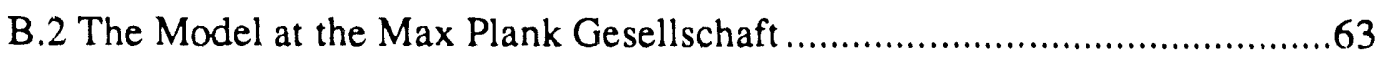

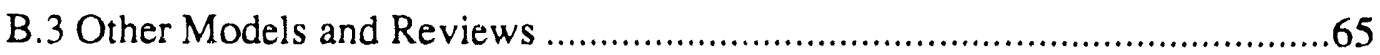




\section{List of Tables}

1. Estimates of new production by various methods

\section{List of Figures}

1. Basic physics of the upper ocean ................................................................... 3

2. Simplified nutrient cycle modeled by Peng et al., 1987 ....................................... 9

3. Detailed nutrient cycle in the upper ocean ....................................................... 11

4. Strategies of new production measurement ............................................... 13

5. Schematic of the integrated turbulent kinetic energy models................................. 23

6. Schematic of the shear instability models ................................................ 24

7. Schematic of the Price et al. (1986) shear instability model ................................. 26 


\section{Introduction}

This report summarizes our current understanding of the physical, chemical, and biological processes that control the natural cycling of $\mathrm{CO}_{2}$ in the surface ocean. The report is written on a basic, general level, with the goal of providing the background necessary for non-specialists to approach this inierdisciplinary field. Because the physics of mixing at the ocean surface creates the essential framework for the chemistry and biology, and because the literature on surface ocean mixing is extensive, a major focus of the report is to review existing mixed layer models for the upper ocean and their implementation in global ocean circulation models. The report will focus on the salient results and omit detailed derivations, which are available in the primary literature.

A brief description of surface ocean physics is given in section 2 . Building on this background, the biological and chemical processes that influence surface ocean $\mathrm{pCO}_{2}$ ( $\mathrm{pH}$ behavior of the carbonate buffer system, controls of gas solubility, nutrient cycling, and the export of sinking organic particles) are discussed in section 3. Although one link in the nutrient cycle appears to be diapycnal mixing of high-nutrient water through the thermocline, the topic of diapycnal mixing is not addressed in this report. Section 4 reviews the "bulk formulas" by which air-sea fluxes of momentum, heat, and gases are calculated. Section 5 is a review and comparison of the three existing families of mixed layer models (the "integrated TKE" models, the "shear instability" models, and the "turbulence closure" models). This section summarizes the history of sea ice models and hybrid mixed layer models which incorporate sea ice dynamics. To make the text of this review more concise, annotated bibliographies of mixed layer models, sorted by model type, are relegated to Appendix A. Section 6 explores the treatment of the mixed layer in large-scale ocean circulation models, and summarizes the various strategies which have been used for reconciling the limits of available computational resources with the need for detail in the upper ocean. Similarly to the treatment of mixed layer 
models, an annotated bibliography of general circulation models has been included in Appendix B. 


\section{The Structure of the Upper Ocean}

The vertical structure of water temperature and solutes (salinity, nutrients, $\mathrm{pCO}_{2}$ ) in the upper ocean is controlled by wind-driven mixing and density stratification. Kinetic energy input from the wind homogenizes the surface water down to the base of the mixed layer (Figure 1). On time scales of hours to months, the overall stratification is determined by the heat fluxes to and from the atmosphere. In summer, the mixed layer warms and shoals, separated from cooler water below by the seasonal thermocline. As winter approaches, surface cooling deepens the mixed layer, destroying the seasonal thermocline. In some high-latitude regions, surface cooling leads to dee ${ }_{i}$, convective mixing that is responsible for the ventilation of the thermocline (Luyten et al., 1983) and the deep ocean. On the time frame of years, the stratification of the upper ocean is maintained by upwelling of denser water from the deep ocean.

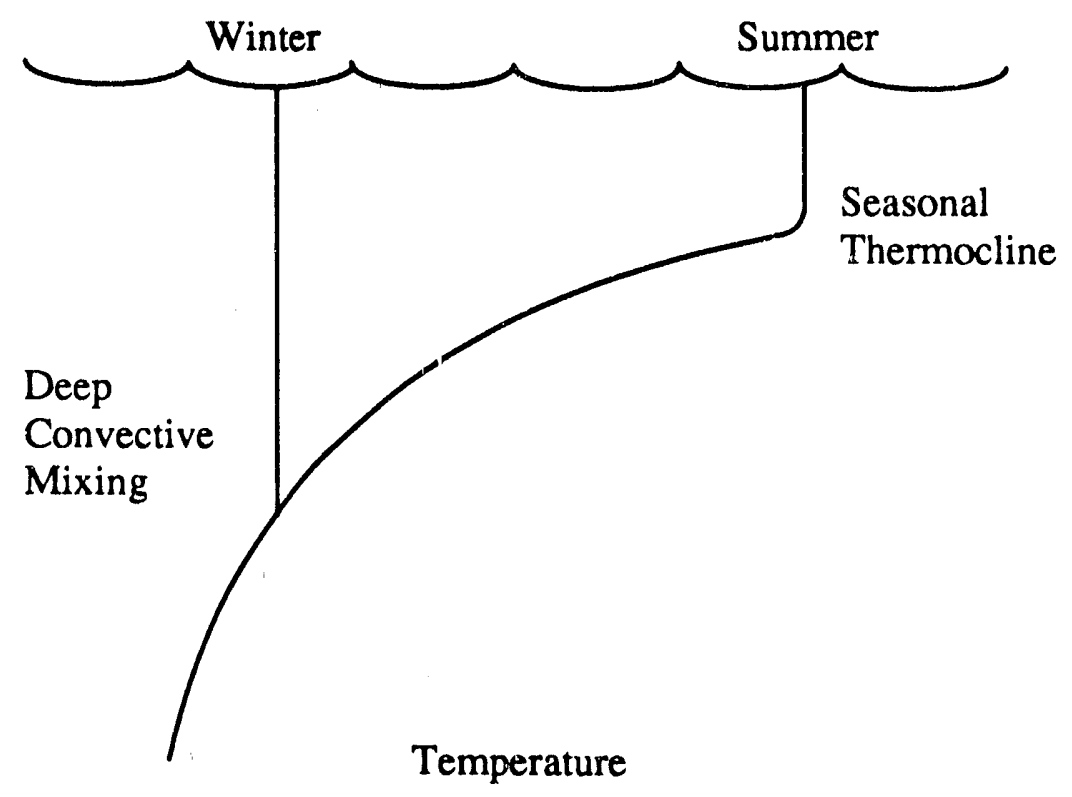

Figure 1. Schematic structure of the upper ocean. 
The stratification of the mixed layer base and thermocline acts as a barrier to vertical eddy diffusion (Denman and Gargett, 1988). The mixing impedance between the ocean surface and deeper water shapes many of the processes affecting oceanic uptake of fossil-fuel $\mathrm{CO}_{2}$, such as the nutrient supply for primary production or ventilation of the thermocline. 


\section{Biological and Chemical Processes in the Upper Ocean}

The modeling of $\mathrm{pCO}_{2}$ at the ocean surface is in many ways analogous to the modeling of sea surface temperature, in that both are affected by exchange with the atmosphere and by mixing across the mixed layer base. Since SST appears to be crucial to the understanding of the El Nido Southern Oscillation climate fluctuations (for a review, see Enfield, 1989), methods for modeling SST in the oceans, especially the tropical Pacific, are well developed. The parallels between modeling of $\mathrm{pCO}_{2}$ and of SST break down in several important ways, however, because of biological and chemical processes which affect surface ocean $\mathrm{pCO}_{2}$ but which have no analog in the processes that control SST.

During the summer, surface heating is concentrated in a shallow mixed layer, and the sea surface temperature rises. The equilibrium atmospheric partial pressure of $\mathrm{CO}_{2}$ increases with temperature, so that a water parcel in equilibrium with the atmosphere in the winter would be supersaturated in the summer, if no other processes were active. Biological export of carbon from the surface ocean as sinking organic particles has a direct and opposite influence on the $\mathrm{pCO}_{2}$ of the surface water, more than offsetting the trend in $\mathrm{pCO}_{2}$ generated by te $\mathrm{n}_{j}^{\prime}$ erature alone (Peng et al., 1987). The $\mathrm{pH}$ equilibrium reactions of the carbonate system buffer the seawater to changes in $\mathrm{pCO}_{2}$, such that roughly 10 times as mucn $\mathrm{CO}_{2}$ is absorbed per unit change in $\mathrm{pCO}_{2}$ relative to the case of an unbuffered gas.

\subsection{A Summary of Carbonate Buffer System Chemistry}

The carbonate buffer system can be summarized as follows. Atmospheric $\mathrm{CO}_{2}$ dissolves in seawater and is hydrated to form carbonic acid, $\mathrm{H}_{2} \mathrm{CO}_{3}$. Carbonic acid is divalent; that is, it can undergo two de-protonation reactions to form bicarbonate $\left(\mathrm{HCO}_{3}{ }^{-}\right)$, and carbonate $\left(\mathrm{CO}_{3}{ }^{-}\right)$. The co-existence of these species in seawater creases a chemical buffer system, regulating the $\mathrm{pH}$ and the $\mathrm{pCO}_{2}$ of the oceans. Most of the 
inorganic carbon in the ocean exists as bicarbonate $(\sim 88 \%)$, with the concentrations of carbonate ion and $\mathrm{CO}_{2}$ comprising about $11 \%$ and $1 \%$, respectively. A standard text for this topic is Stumm and Moigan (1981).

\subsubsection{Aqueous Chemistry}

The hydration reaction of $\mathrm{CO}_{2}$ to form $\mathrm{H}_{2} \mathrm{CO}_{3}$ is described by the following equilibrium system:

$$
\mathrm{H}_{2} \mathrm{CO}_{3}=\mathrm{CO}_{2}+\mathrm{H}_{2} \mathrm{O}, \quad \mathrm{K}=\frac{\left\{\mathrm{CO}_{2}(\mathrm{aq})\right\}}{\left\{\mathrm{H}_{2} \mathrm{CO}_{3}\right\}}
$$

where $\mathrm{K}$ is a thermodynamic equilibrium constant. [Note: the activity of a solute represents the apparent concentration, which approaches the actual concentration near the limit of infinite dilution. Activity is denoted by braces (e.g., $\left\{\mathrm{CO}_{2}\right\}$ ), whereas concentrations are indicated by brackets (as $\left[\mathrm{CO}_{2}\right]$ ). A thermodynamic equilibrium constant is defined in terms of species activities, as above.]

Analytical determination of the relative activities of $\mathrm{H}_{2} \mathrm{CO}_{3}$ and $\mathrm{CO}_{2}$ is difficult, so it is convenient to group the two species together using the notation:

$$
\mathrm{H}_{2} \mathrm{CO}_{3}{ }^{*}=\mathrm{H}_{2} \mathrm{CO}_{3}+\mathrm{CO}_{2}
$$

Carbonic acid undergoes de-protonation to form bicarbonate and carbonate ion. The equilibrium expression for the first $\mathrm{pH}$ reaction is expressed using the $\mathrm{H}_{2} \mathrm{CO}_{3}{ }^{*}$ notation (this is called a composite equilibrium expression):

$$
\mathrm{H}_{2} \mathrm{CO}_{3}{ }^{*}=\mathrm{H}^{+}+\mathrm{HCO}_{3}^{-}, \quad \mathrm{K}_{1}=\frac{\left\{\mathrm{H}^{+}\right\}\left\{\mathrm{HCO}_{3}^{-}\right\}}{\left\{\mathrm{H}_{2} \mathrm{CO}_{3}{ }^{*}\right\}}
$$

The second dissociation reaction is described by 


$$
\mathrm{HCO}_{3}^{-}=\mathrm{H}^{+}+\mathrm{CO}_{3}=, \quad \mathrm{K}_{2}=\frac{\left\{\mathrm{H}^{+}\right\}\left\{\mathrm{CO}_{3}=\right\}}{\left\{\mathrm{HCO}_{3}^{-}\right\}}
$$

For convenience, apparent equilibrium constants, denoted by primes, can be defined in terms of concentrations of the carbonate species, rather than activities, as

$$
\mathrm{K}_{1}^{\prime}=\frac{\left\{\mathrm{H}^{+}\right\}\left[\mathrm{HCO}_{\left.3^{-}\right]}\right.}{\left[\mathrm{H}_{2} \mathrm{CO}_{3}^{*}\right]}, \quad \mathrm{K}_{2}^{\prime}=\frac{\left\{\mathrm{H}^{+}\right\}\left[\mathrm{CO}_{3}=\right]}{\left[\mathrm{HCO}_{3}^{-}\right]} \text {. }
$$

Values for $\mathrm{K}_{1}^{\prime}$ and $\mathrm{K}_{2}^{\prime}$, respectively, are $10^{-6.00}$ and $10^{-9.11}$, at $1 \mathrm{~atm}$ pressure, $35 \%$ salinity and a ternperature of $25^{\circ} \mathrm{C}$ (Stumm and Morgan, 1981). The effect of temperature on the $\mathrm{pCO}_{2}$ is addressed in the following section.

The behavior of the carbonate buffer system in seawater may be counter-intuitive. For example, when $\mathrm{cr}$ bonate ion is removed from solution (such as by formation of solid $\mathrm{CaCO}_{3}$ ), bicarbonate ion undersgces a disproportionation reaction (until the equilibrium expressions (5) are satisfied):

$$
2 \mathrm{HCO}_{3}^{-}=\mathrm{H}_{2} \mathrm{CO}_{3}+\mathrm{CO}_{3}=
$$

The net result of this transaction is to increase the $\mathrm{pCO}_{2}$ of the water parcel as $\mathrm{CO}_{3}=$ is removed. (Contrast this with the simple-minded expectation that removal of a carbon species $\left(\mathrm{CO}_{3}=\right)$ should reduce the concentrations of all other carbon species). Natural variations in seawater $\mathrm{pH}$ cause the relative concentrations of $\mathrm{CO}_{2}$ and $\mathrm{CO}_{3}=$ to vary inversely with each other, like the seats on a teeter-totter, while the relative changes in the concentation of $\mathrm{HCO}_{3}^{-}$are much smaller.

The carbonate buffer system as written above has two degrees of freedom; that is, two measurements are required to specify the system entirely. The "alkalinity" of a sample is defined as the amount of acid required to neutralize all of the weak bases in the solution (primarily bicarbonate and carbonate ion), and can be measurea by $\mathrm{pH}$ titration 
(see Stumm and Morgan, 1981). Other practical measurements include the concentration of total $\mathrm{CO}_{2}$ [defined as $\mathrm{CO}_{2}+\mathrm{HCO}_{3}^{-}+\mathrm{CO}_{3}=$ : measurement technique by Johnson et al., 1985], and the $\mathrm{pCO}_{2}$ (Takahashi et al., 1982). Measuring $\mathrm{pCO}_{2}$ directly is the most reliable way of calculating air-sea $\mathrm{pCO}_{2}$ differences.

\subsubsection{IJas Equilibrium Chemistry}

The equilibrium partitioning of $\mathrm{CO}_{2}$ between atmospheric and dissolved states is described by Henry's law:

$$
\mathrm{K}_{\mathrm{H}}=\frac{\left[\mathrm{CO}_{2}\right]}{\mathrm{pCO}_{2}}
$$

where $\mathrm{K}_{\mathrm{H}}$ is called the Henry's law constant. Values for $\mathrm{pK}_{\mathrm{H}}$ are 1.11 and 1.47 at temperatures of 0 and $25^{\circ} \mathrm{C}$. The $\mathrm{pCO}_{2}$, or "partial pressure" of $\mathrm{CO}_{2}$, is defined as the gas pressure exerted by $\mathrm{CO}_{2}$ in the head space above a water sample at equilibrium. Seawater that is not in gas-exchange equilibrium with the atmosphere will have a $\mathrm{pCO}_{2}$ that is different from the atmospheric value.

The Henry's law coefficient, $\mathrm{K}_{\mathrm{H}}$, varies strongly with temperature, tending to higher $\mathrm{pCO}_{2}$ at higher temperature. The $\left[\mathrm{CO}_{2}\right]_{\mathrm{aq}}$ is also affected by temperature dependence of $\mathrm{K}_{1}^{\prime}$ and $\mathrm{K}_{2}^{\prime}$ (for a full treatment of these effects, see Broecker and Peng, 1982, page 150). The net temperature dependence of seawater $\mathrm{pCO}_{2}$ is an increase by about $4 \%$ per degree Celsius.

The $\mathrm{pCO}_{2}$ of sea water is buffered by the carbonate system, relative to a non-pH active gas like $\mathrm{O}_{2}$. This is because, a change in $\mathrm{pCO}_{2}$ must be accompanied by changes in the concentrations of bicarbonate and carbonate ions. At the normal pH of seawater, the carbonate buffer system provides an effective reservoir for $\mathrm{CO}_{2}$ that is roughly 10 times larger than the reservoir for an unbuffered gas like $\mathrm{O}_{2}$. Therefore, the equilibration time of seawater $\mathrm{pCO}_{2}$ is roughly 10 times slower than that for $\mathrm{O}_{2}$. This 
Summer

\begin{tabular}{|c|}
\hline \multicolumn{2}{|l|}{ Mixed Layer } \\
$\qquad \begin{array}{l}\text { Sinking } \\
\text { Particles } \\
\text { Remineralization }\end{array}$ \\
Thermocline
\end{tabular}

Winter

$$
\text { Mixed Layer }
$$

Entrainment

Thermocline

Figure 2. Simplified nutrient cycle in the upper ocean used by Peng et al., 1987.

factor of 10 is called the Revelle buffer factor.

Because of the slow equilibration time for seawater $\mathrm{pCO}_{2}$ and the strong temperature effect, the $\mathrm{pCO}_{2}$ of warm waters in the surface ocean tends to be higher than the atmospheric value (supersaturated), while colder waters tend to be undersaturated (see Volk and Liu, 1988).

\subsection{The Biological Pump and Nutrient Cycling}

Biological production in the surface ocean produces particles which sink into deeper waters, where they may re-dissolve. This process (called the "biological pump") maintains lower concentrations of carbon and nutrients in the surface ocean than within 
the thermocline waters below. Removal of dissolved $\mathrm{CO}_{2}$ to form organic matter lowers the steady-state sea surface $\mathrm{pCO}_{2}$ than would result from an abiotic ocean. Less important quantitatively is the removal of dissolved $\mathrm{CO}_{3}=$ to form solid $\mathrm{CaCO}_{3}$ (the minerals calcite and aragonite), which tends to increase $\mathrm{pCO}_{2}$ (see section 3.1.1).

Much of the organic matter produced by photosynthesis is oxidized within the mixed layer; hence nutrients can be recycled several times before they are exported as sinking organic matter. The rate of total ("gross") photosynthesis less phytoplankton respiration is called the "net" production. "New" production is defined as the rate of assimilation of "new" nutrients entering the euphotic zone (Dugdale and Goering, 1967), which is balanced, in steady state, by export of nutrients incorporated in sinking organic matter (Eppley and Peterson, 1979). The fraction of new production to total production is called the f-ratio. Recycled nitrogen exists as ammonia, whereas "new" nitrogen exists as nitrate, so the f-ratio is traditionally measured as the relative phytoplankton uptake rates of $15 \mathrm{~N}$-labeled nitrate and ammonia (Dugdale and Goering, 1967). Prediction of the f-ratio based either on first principals or on empirical observations is still elusive (Eppley and Peterson, 1979; Platt et al., 1989; Sarmiento et al., 1989).

A simple model of nutrient cycling in the upper ocean was presented by Peng et al. (1987), to reproduce data from the Greenland sill. The upper box of the model is the mixed layer; the lower box represents the thermocline (Figure 2). The boundary between the boxes fluctuates according to the observed annual cycle of mixed layer depth. Both boxes are well-mixed. Organic carbon is produced in the upper box and regenerated within the lower box. When the mixed layer deepens in the winter, nutrients from the deep box are entrained into the mixed layer. The model neglects the diffusive flux of nutrients across the boundary (either between the two soxes or from the deep ocean into the lower box) and the sinking flux of particles at the bottom boundary. However, the annual cycle of surface water nutrient concentration and the dissolved $\mathrm{O}_{2}$ and $\mathrm{CO}_{2}$ 
Nitrate

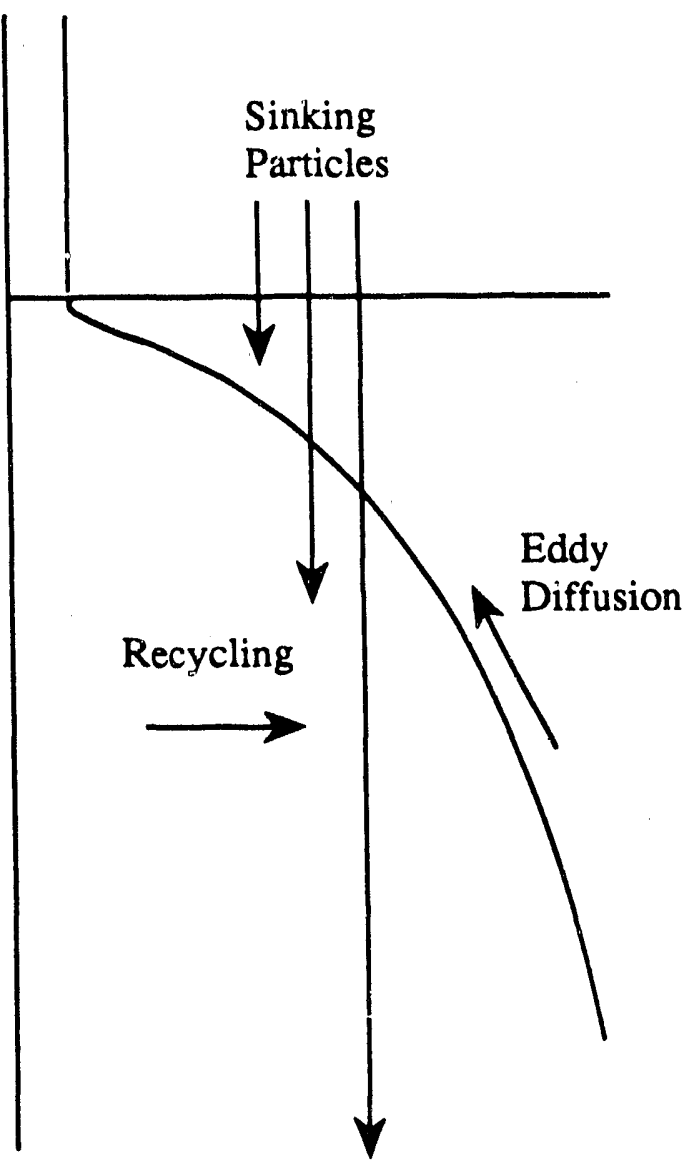

Summer
Nitrate

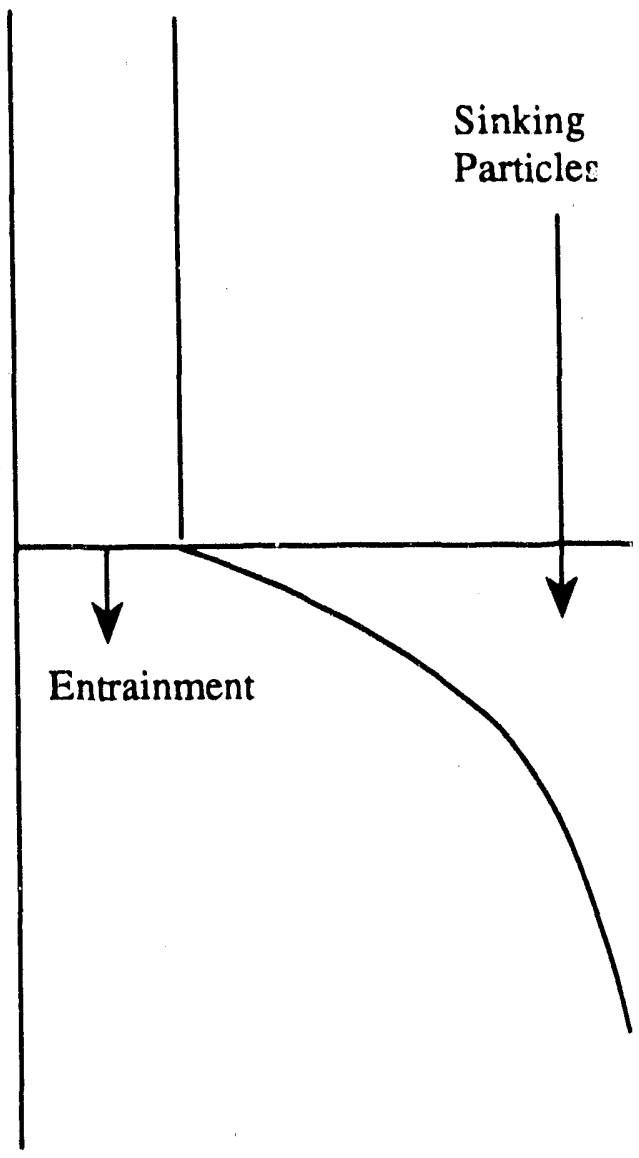

Winter

Figure 3. Detailed nutrient structure of the upper ocean.

predicted by this simple model are similar to the observations.

When the vertical density structure of the water column and the processes of nutrient transport and regeneration are considered in greater detail, the picture becomes more complex (Figure 3). Although most of the organic matter that falls from the euphotic zone is regenerated in the upper few hundreds of meters of the water column, 


\begin{tabular}{|c|c|c|c|}
\hline Location & Method & Reference & $\begin{array}{l}\text { Carbon Flux, } \\
\mathrm{g} \mathrm{C} \mathrm{m}^{-2} \mathrm{y}^{-1}\end{array}$ \\
\hline \multirow[t]{2}{*}{$\begin{array}{l}\text { oligotrophic } \\
\text { eastern Atlantic }\end{array}$} & $\begin{array}{l}\text { Vertical eddy } \\
\text { diffusion of nitrate }\end{array}$ & $\begin{array}{l}\text { Lewis, et al. } \\
\text { (1986) }\end{array}$ & $0.06-27$ \\
\hline & $15_{\mathrm{N}}$ uptake & Harrison (1983) & $20-30$ \\
\hline \multirow[t]{3}{*}{ Bermuda } & \multirow[t]{3}{*}{$\mathrm{O}_{2}$ mass balance } & $\begin{array}{l}\text { Spitzer and Jenkins } \\
(1989)\end{array}$ & $25-66$ \\
\hline & & $\begin{array}{l}\text { Jenkins and } \\
\text { Goldman (1985) }\end{array}$ & $\sim 50$ \\
\hline & & $\begin{array}{l}\text { Musgrave et al. } \\
(1989)\end{array}$ & $28-37$ \\
\hline \multirow{6}{*}{$\begin{array}{l}\text { Station P: } \\
\text { Subarctic Pacific }\end{array}$} & \multirow[t]{2}{*}{$\mathrm{O}_{2}$ mass balance } & Emerson (1987); & $30-100$ \\
\hline & & $\begin{array}{l}\text { Emerson et al (in } \\
\text { preparation) }\end{array}$ & $28-56$ \\
\hline & $15 \mathrm{NO}_{3}$ uptake & $\begin{array}{l}\text { Wheeler and } \\
\text { Kokkinakis (1990) }\end{array}$ & $99 \pm 31$ \\
\hline & $\begin{array}{l}\text { Sediment trap } \\
\text { fluxes }\end{array}$ & $\begin{array}{l}\text { Welschmeyer } \\
\text { (1990) }\end{array}$ & 29 \\
\hline & $\begin{array}{l}\text { Buildup of } \\
\text { particulate } N\end{array}$ & \multirow[t]{2}{*}{$\begin{array}{l}\text { Emerson et al (in } \\
\text { preparation }\end{array}$} & \multirow{2}{*}{$\frac{+18}{47}$} \\
\hline & $\begin{array}{l}\text { Total particulate } \\
\text { production }\end{array}$ & & \\
\hline $\begin{array}{l}\text { Beta triangle: } \\
\text { North Atlantic }\end{array}$ & $\begin{array}{l}\text { Oxygen utilization } \\
\text { rate }\end{array}$ & Jenkins (1982) & $55 \pm 5$ \\
\hline $\begin{array}{l}\text { VERTEX: North } \\
\text { Pacific }\end{array}$ & $\begin{array}{l}\text { Near-surface } \\
\text { sediment trap } \\
\text { fluxes }\end{array}$ & Martin et al (1987) & 130 \\
\hline
\end{tabular}

Table 1. Representative estimates of new production by various methods.

some fraction [ $25 \%$ at 200 meters (Martin et al., 1987)] inevitably escapes from the deepest reach of the mixed layer; it is this fraction that drives respiration in the deep water and benthos. This loss must be balanced by upward diffusion or advection of nutrients.

It is possible to measure new production at several links in the cycle, using independent techniques. For example, the upward diffusive flux of nutrients can be 


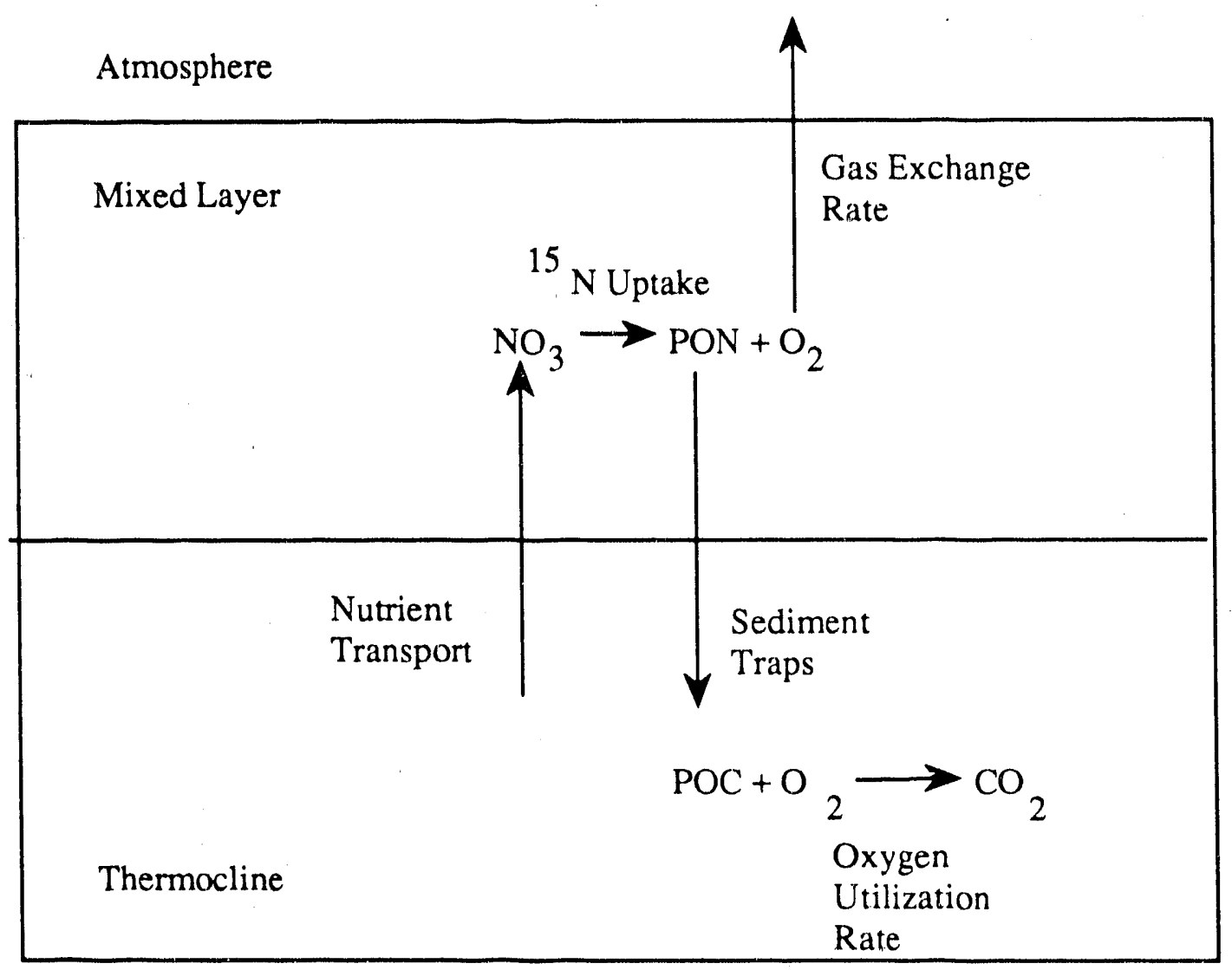

Figure 4. Strategies of new production measurement.

estimated using tracer or microstructure techniques, the new production rate using $15 \mathrm{~N}$ uptake or an $\mathrm{O}_{2}$ flux balance, the thermocline oxygen utilization rate using tritium and ${ }^{3} \mathrm{He}$, and the particulate nutrient export rate using sediment traps (see Figure 4 and Table 1). In steady state, these fluxes should all be equivalent.

In some locations (for exampl station Papa: see table 1), estimates of new production by various methods agree to within the uncertainty of the measurements. However, a number of problems remain. Until recently, new production estimates made using bottle growth experiments were significantly inhibited by trace metal contamination (Fitzwater et al., 1982; Marra and Heinemann, 1984). Also, our understanding of the transport of nutrients by eddy diffusion is problematic, in that the processes that control mixing are still uncertain (Gregg, 1987). In particular, salt 
fingering (Hamilton et al., 1989) and boundary mixing introduce order-of-magnitude uncertainty in estimates of basinwide diapycnal mixing rates.

More significantly, data exists which suggests that the paradigm itself (nutrient import by continuous vertical eddy diffusion and export by particle sinking) may be insufficient in some locations. In parts of the tropical Pacific, nitrate is undetectable to 50 meters deeper than the deepest reach of the mixed layer. In this location, there can be no vertical eddy transport of nitrate into the mixed layer, and yet there is measurable new production (Hayward, 1987). A similar situation exists near Bermuda; Spitzer et al. (1990) have suggested that transport of nutrients into the mixed layer there might be an episodic process not well described by the eddy diffusion model. Finally, a new method for measuring dissolved organic carbon (DOC) recently revealed high concentrations of DOC in oligotrophic ocean surface water (Suzuki et al, 1985). The profiles of this "extra" DOC in the water column suggest that it is biologically labile. If these observations prove to be correct, the transport of nutrients by this previously hidden pool could play a major role in the biological and chemical cycling in the upper ocean (Toggweiler, 1989; Sarmiento et al., 1989; Najjar, 1990).

In conclusion, the full cycling of nutrient supply, use, and removal in the surface ocean is only crudely understood, and will pose limits on the predictive ability of a carbon cycle ocean circulation model.

\subsection{Limits to Primary Production}

In many regions of the world's oceans (the North Pacific, the Southern Ocean, and the equatorial Pacific) surface production does not fully deplete the surface nutrients during the summer growing season. Simple box models of the ocean - atmosphere system have shown that the atmospheric $\mathrm{pCO}_{2}$ is extraordinarily sensitive to the degree of nutrient utilization in the high-latitude oceans (for example, Sarmiento et al., 1988). If nutrients in the high-latitude surface waters were completely utilized by primary 
production, then the pre-industrial atmospheric $\mathrm{pCO}_{2}$ could have been as low as 165 ppm; lower efficiency of nutrient use could have increased $\mathrm{pCO}_{2}$ to as high as $425 \mathrm{ppm}$ (pre-industrial atmospheric $\mathrm{pCO}_{2}$ was $280 \mathrm{ppm}$ ). Obviously, understanding the factors limiting growth in these regions, and predicting how they might respond to changing climate, is crucial to global $\mathrm{CO}_{2}$ modeling. Unfortunately, the limitation of phytoplankton growth is still a subject of research and debate.

One hypothesis is that the rate of primary production is limited by grazing by microzooplankton (Livans and Parsiow, 1985; Frost, 1987; Fenchel, 1988). Microzooplankton have short reproductive cycles, and so can respond quickly to variations in primary production, in contrast to macrozooplankton, which have annual reproductive cycles. In the North Atlantic, where the spring bloom depletes the surface nutrients, it could be that the phytoplankton escape predation in the spring because of the deeper wintertime mixed layer [which depletes microzooplankton stocks to low levels (Frost, 1987)].

Another hypothesis involves the micronutrient iron, which may be limiting the primary production rate in some regions (Martin and Fitzwater, 1988; Martin and Gordon, 1988). Iron is thought to be used by phytoplankton in the enzymatic system for conversion of nitrate to ammonia; thus, a limitation of iron would inhibit new (nitratebased) growth (Reuter and Ades, 1987; Martin et al., 1989). Growth experiments on phytoplankton samples from the North Pacific were performed both with and without the addition of trace quantities of iron, and in most cases, the iron-added system showed enhanced phytoplankton growth rates relative to the low-Fe blank. Iron is supplied to the surface ocean by atmospheric flux of continental dust (Martin and Gordon, 1988), and regions of low nutrient utilization tend to correspond to regions of low atmospheric particulate input.

In summary, the extent to which phytoplanktcn consume the available nutrients in 
the high-latitude oceans has a primary impact on the $\mathrm{pCO}_{2}$ of the atmosphere. The factors limiting growth in these regions are still subject to debate. Neither of the two available hypotheses can be regarded, as proven, nor are they necessarily mutually exclusive. The possibility exists that the limits to growth may change with changes in climate, which complicates prediction of future atmospheric $\mathrm{pCO}_{2}$.

\subsection{Recycling Efficiency in the Euphotic Zone}

The other field observation that must be reproduced by a biological ecosystem model is the amount of recycling of the nutrients, or the f-ratio. This requires an understanding of the processes of particle export and sinking (Sarmiento et al, 1989). Understanding the processes that control the f-ratio would help interpretation of the abundant ocean color data from satellites in terms of new productivity rates for comparison with $\mathrm{CO}_{2}$ modeling studies. 


\section{Physical Processes}

We have seen that the depth of the surface mixed layer is a primary driver for the processes that control the surface ocean $\mathrm{pCO}_{2}$. Examples of these processes are the removal of $\mathrm{CO}_{2}$ by the spring bloom (which responds to shaaling of the mixed layer), $\mathrm{CO}_{2}$ de-gassing in response to summer sea surface warming (which is mixingdependent), and the entrainment of high- $\mathrm{pCO}_{2}$ deeper water into the mixed layer during fall cooling. The fluxes of heat, momentum, fresh water, and light provide the boundary conditions and energy sources that drive the dynamics of the mixed layer. We will focus on these fluxes and conditions before looking at the mixed layer models that have been developed.

\subsection{Momentum}

The wind stress on the ocean surface can be calculated from the square of the wind speed at a height of 10 meters $\left(\mathrm{U}_{10}\right)$, the density of air $\left(\rho_{\text {air }}\right)$, and a drag coefficient (CD) (from Wu, 1982):

$$
\tau=\rho_{\text {air }} \mathrm{C}_{\mathrm{D}} \mathrm{U}_{10^{2}}
$$

The drag coefficient, $C_{D}$ is often represented by a constant. However, the high seas which result from heavy winds tend to increase $C_{D}$. Values of the drag coefficient as a function of wind speed were summarized by Wu (1982):

$$
\mathrm{C}_{10}=10^{-3}\left(0.8+0.065 \mathrm{U}_{10}\right)
$$

where $\mathrm{U}_{10}$ is the wind velocity at a height of 10 meters. When this expression is incorporated into (8), the momentum flux into the surface layer scales as the wind speed to the third power. Since the momentum flux is a non-linear function of the wind speed, the use of wind speeds averaged over time scales of weeks to months results in underestimation of wind-driven mixing (for example, see Rosati and Miyakoda, 1988) 


\subsection{Heat}

Heat is transferred between the surface ocean and the atmosphere by the mechanisms of evaporation (latent heat flux), radiation (both direct short-wave sunlight and net long-wave back-radiation), and conduction (the sensible heat flux). The "bulk" formulas for latent $(\mathrm{H})$ and sensible $\left(\mathrm{L}_{\mathrm{V}} \mathrm{E}\right)$ heat fluxes are similar to the momentum flux equation in that they involve drag (transfer) coefficients $\left(\mathrm{C}_{\mathrm{H}}\right.$ for latent and $\mathrm{C}_{\mathrm{E}}$ for evaporative) and the difference in temperature ( $T$, where the subscript "s" denotes water surface, and "a" denotes air) or water saturation (relative humidity, q), respectively (from Gill, 1982):

$$
H=\rho_{\text {air }} c_{p} C U\left(T_{s} \cdot T_{a}\right)
$$

and

$$
\mathrm{L}_{\mathrm{V}} \mathrm{E}=\rho_{\mathrm{air}} \mathrm{L}_{\mathrm{V}} \mathrm{C}_{\mathrm{E}} \mathrm{U}_{10}\left(\mathrm{q}_{\mathrm{s}}-\mathrm{q}_{\mathrm{a}}\right)
$$

The best value for $\mathrm{C}_{\mathrm{H}}$ ranges from $0.83 * 10^{-3}$ (unstable atmospheric conditions) to 1.10 * $10^{-3}$ (stable conditions). $C_{E}$ is estimated to be $1.5 * 10^{-3}$.

The formulation for the heat flux caused by radiative transfer is somewhat more complicated. The input radiation $\left(\mathrm{Q}_{\mathrm{I}, 0}\right)$ can be described as a function of latitude and season (Frouin et al., 1989). Some of the incoming radiation is blocked by clouds in the atmosphere. The effect of clouds represents a major uncertainty in the heat balance of the surface ocean (Seager et al., 1988; Wigley, 1989; Mitchell et al., 1989). In addition to oceanic heat gain by incoming light, some heat is lost by outgoing blackbody radiation. There exist several formulations to calculate the net radiative heat flux; the following was presented by Gill (1982):

$$
\mathrm{Q}_{\mathrm{I}}=\mathrm{Q}_{\mathrm{I}, 0}\left(1-\alpha_{\mathrm{S}}\right)\left(1-0.7 \mathrm{n}_{\mathrm{c}}\right)
$$


and

$$
\mathrm{Q}_{\mathrm{B}}=0.985 \sigma \mathrm{T}_{\mathrm{s}}^{4}\left(0.39-0.05 \mathrm{e}_{\mathrm{a}}^{1 / 2}\right)\left(1-0.6 \mathrm{n}_{\mathrm{c}}^{2}\right)
$$

where $Q_{I}$ is the downward radiative heat flux, $Q_{b}$ is the upward long-wave radiation, $\alpha_{S}$ is the surface albedo (roughly 0.3 ), $\mathrm{n}_{\mathrm{c}}$ is the fractional cloud cover, $\sigma$ is the Boltzmann constant, $\mathrm{T}_{\mathrm{S}}$ is the sea surface temperature, and $\mathrm{e}_{\mathrm{a}}$ is the vapor pressure of the atmosphere (mbar). The standard deviation of the uncertainty of the total heat flux has been estimated to be on the order of $25 \mathrm{~W}^{\prime} \mathrm{m}^{-2}$ (Weare et al., 1981; see also Seager et al., 1988; Davis et al., 1981a). For comparison, the global average heat flux is on the order

of $240 \mathrm{~W} \mathrm{~m} \mathrm{~m}^{-2}\left(\mathrm{Gi}^{\prime} \mathrm{i}, 1982\right)$, and the perturbation due to the anthropogenic $\mathrm{CO}_{2}$ will be approximately $4 \mathrm{~W} \mathrm{~m}^{-2}$ (Lorius et al., 1990).

\subsection{Bio-Optics}

The vertical distribution of photosynthesis is determined by the penetration of light into the upper ocean and by the depth profile of nutrients. Light perietration (as opposed to absorbtion at the surface) may also have an effect on the sea surface temperature (Woods, 1986). Ocean waters have been divided into three optical types (Jerlov, 1976) according to the optical characteristics of their suspended particulate material. In the open ocean, the concentration of suspended detritus is low, and the optical properties are largely regulated by the abundance of phytoplankton chlorophyll. The profile of light energy with depth can be approximated by an exponential (from Parsons et al., 1984):

$$
\mathrm{Q}(\mathrm{z})=\text { Qblue, } \mathrm{I} \mathrm{e}^{-\mathrm{k}^{\prime} \mathrm{z}}
$$

and

$$
\mathrm{k}^{\prime}=.04+.0088 \mathrm{Chl}+.054 \mathrm{Chl}^{2 / 3}
$$


where Qblue,I is the incidence of blue visible light at the sea surface (roughly half of the total radiative energy), $\mathrm{Chl}$ is the concentration of chlorophyll, and a and b are constants (for more detail, see Morel, 1988). Only the blue, penetrating fraction of the light is photosynthetically active radiation (PAR). The rest of the light energy $\left(Q_{\text {red,I }}\right)$ is red light, which is absorbed in the top meter. State-of-the-art models of PAR and light energy input to the mixed layer include such factors as latitude, season, and angle of solar input (Sethyendranath and Platt, 1988; Morel, 1988).

\subsection{Gas Exchange}

The exchange rate of gases from the surface ocean to the atmosphere also has a wind speed dependence. A summary of measured field data is presented in Liss and Merlivat (1986). The gas exchange rate can be described by

$$
\text { Flux }=\mathrm{K}_{\mathrm{W}}\left(\mathrm{pCO}_{2} \mathrm{~atm}-\mathrm{pCO}_{2} \text { sea surface }\right)
$$

The gas exchange coefficient $\left(\mathrm{K}_{\mathrm{W}}\right)$ varies as a function of the wind speed as

$$
\begin{aligned}
& \mathrm{K}_{\mathrm{W}}=.17 \mathrm{U}_{10} \quad \text { for } \mathrm{U}_{10}<3.6 \mathrm{~m} / \mathrm{s} \quad \alpha \mathrm{Sc}^{-2 / 3} \\
& =2.85 \mathrm{U}_{10}-9.65 \quad \text { for } 3.6<\mathrm{U}_{10}<13 \quad \alpha \mathrm{Sc}^{-1 / 2} \\
& =5.9 \mathrm{U}_{10}-49.3 \quad \text { for } \mathrm{U}_{10}>13 \quad \alpha \mathrm{Sc}^{-1 / 2} \text {. }
\end{aligned}
$$

The value of $\mathrm{KW}_{\mathrm{W}}$ also depends on the Schmidt number for the gas (Sc, calculated as $v / D)$. The values of $\mathrm{K}_{\mathrm{W}}$ tabulated above are for a $\mathrm{Sc}=600$; the order dependence of $\mathrm{KW}$ on $\mathrm{Sc}$ is given in the last column. The Schmidt number for $\mathrm{CO}_{2}$ ranges from 1860 to 595 for a temperature range of 0 to $20^{\circ} \mathrm{C}$. Values for $\mathrm{KW}_{\mathrm{W}}$ have been determined in wind tunnels, and in the field by tracer injection, radio-isotopes, and direct measurements. The various measurements are in rough accord, but the uncertainty spans nearly a factor of two (Liss and Merlivat, 1986). 


\section{Overview of Mixed Layer Models}

Given the inputs of heat and energy from the atmosphere, a one-dimensional mixed layer model predicts the depth of the mixed layer, and in some models the shape of the mixed layer base, as a function of time. None of the models treat mixing through the thermocline. There are three basic families of mixed layer models: the "bulk turbulent kinetic energy (TKE)" models, the "shear instability" models, and the "turbulence closure" models (see Martin, 1986; Martin, 1985; Niiler and Kraus, 1977). The assumed physical mechanisms by which entrainment occurs differ fundamentally among the three families, but all are reasonably successful at predicting the observed depth of the mixed layer. Thus the model of choice for incorporation into an ocean GCM may depend on the mechanics of how the models operate as well as on the physical bases for each model. An annotated list of mixed layer model publications is presented in Appendix A.

\subsection{Integrat I TKE, or "Bulk", Models}

The so-called bulk turbulent kinetic energy (TKE) model, initially formulated by Kraus and Turner (1657), treats mixing based on a budget for the integrated TKE of the surface ocean (Rigure 5). A fundamental assumption of this model is that the mixed layer is completely homogeneous in the various state variahles (T, S, U, V, TKE, solutes, etc.). This assumption appears to be well founded in most parts of the surface ocean (see Price et al., 1986; Martin, 1986; Mellor, in press). A heat balance is constructed which accounts for exchange with the atmosphere $\left(\mathrm{L}_{\mathrm{V}} \mathrm{E}\right.$ and $\mathrm{H}$, equations 10 and 11) and fluxes by radiative transfer ( $Q_{I}$, equations 12 and 13), and cooling caused by entrainment of colder water from below (as the mixed layer depth, $h$, changes with time):

$$
h \frac{d T_{S}}{d t}=\Lambda \frac{d h}{d t} \Delta T-\frac{1}{\rho c}\left(Q_{I}-Q_{b l u e, I} e^{-\beta z}-Q_{B}-L_{V} E-H\right)
$$


where

$$
\begin{aligned}
& \Lambda=0 \text { if } \frac{\mathrm{dh}}{\mathrm{dt}}<0, \\
& \Lambda=1 \text { if } \frac{\mathrm{dh}}{\mathrm{dt}}>0,
\end{aligned}
$$

and $T_{S}$ is the sea surface temperature, and $\Delta T$ is the temperature difference across the mixed layer base.

The two degrees of freedom in equation 9 are the sea surface temperature and the depth of the mixed layer; another independent equation is necessary to close the system. The requisite constraint is based on a kinetic energy budget. The source of TKE is the wind stress (a scaling coefficient, $m$, times the "friction velocity" of the wind, $U_{*}{ }^{3}$ ) and the sink is dissipation (D). The residual kinetic energy (the difference between input and dissipation) is transformed into potential energy by mechanical mixing of cold water into the mixed layer (also, the average TKE of the mixed layer decreases as quieter water is entrained):

$$
\frac{1}{2} \frac{\mathrm{dT}_{\mathrm{s}}}{\mathrm{dt}} \mathrm{h}^{2}+\Lambda \Delta \mathrm{Th} \frac{\mathrm{dh}}{\mathrm{dt}}=\mathrm{m} \mathrm{U}^{3}-\mathrm{D}
$$

Since Kraus and Turner (1969), many other workers have used models based on this formulation, and much of the work has centered on the dissipation of turbulence (see Stevenson, 1979, for a review). The generation and dissipation of turbulence is the greatest weakness of this type of model; in the case of dissipation in particular, the link between the model and the actual physics is weak. Some authors scale TKE dissipation as a constant loss rate times the mixed layer depth (Kim 1976, Niiler and Kraus, 1977). Others calculate the dissipation rate as a function of the total amount of mixed-layer TKE, the coriolis parameter (Garwood, 1977) and/or the Monin-Obukhov length scale for turbulence (Gaspar, 1988). To simulate the mixed layer response to hurricanes, Elsberry (1976) used a parameterization for dissipation as a fraction of surface input of 


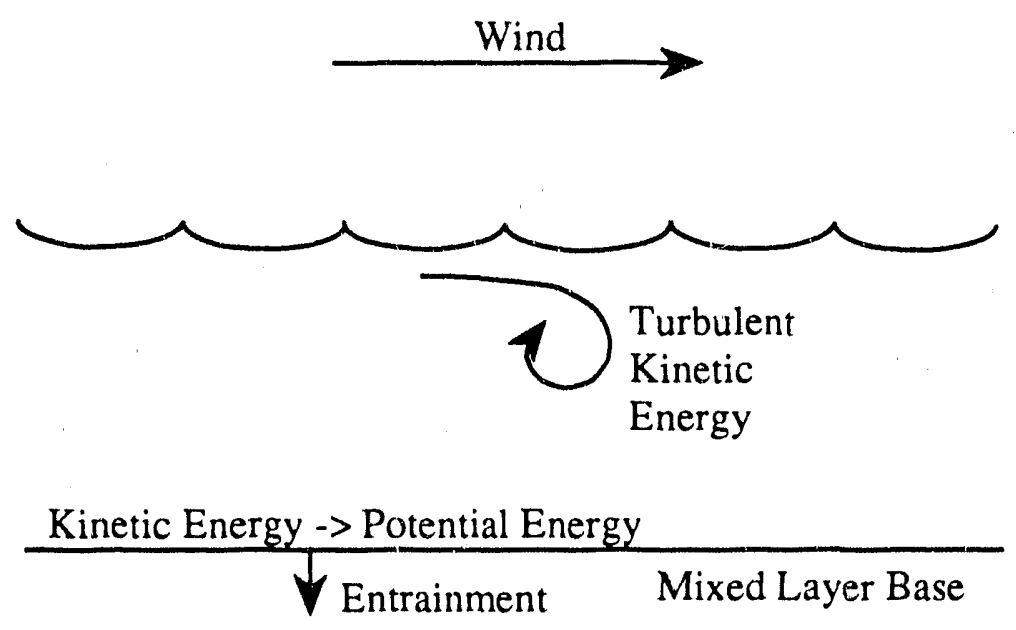

Figure 5. Diagram of the "integrated turbulent kinetic energy" models.

TKE that increases with increasing mixed layer depth.

The other weakness of the bulk TKE family of models is the generation of TKE (calculated as a constant, $m$, times the wind stress). The value of $m$ is "tuned" to fit the model predictions to observed data, and the best value for $\mathrm{m}$ tends to vary with location and conditions [ranging from 0.1 to 0.39 (Martin, 1985) 0.3 to 0.9 (Price et al., 1978) 0.4 to 0.5 (Davis, 1981b)]. The instability of $\mathrm{m}$ and the uncertainty about TKE dissipation certainly detract from the predictive ability of the bulk TKE-type model.

\subsection{Shear Instability Models}

Another potential source of TKE, not considered in the original Kraus-Turner formulation, is the generation of turbulence by current shear (Figure 6). Although the only source of energy to the mixed layer is input by wind, in the shear models this energy is assumed to generate mean flow rather than turbulent energy, and the flow is converted to turbulence at the base of the mixed layer (see Gargett et al., 1979). 


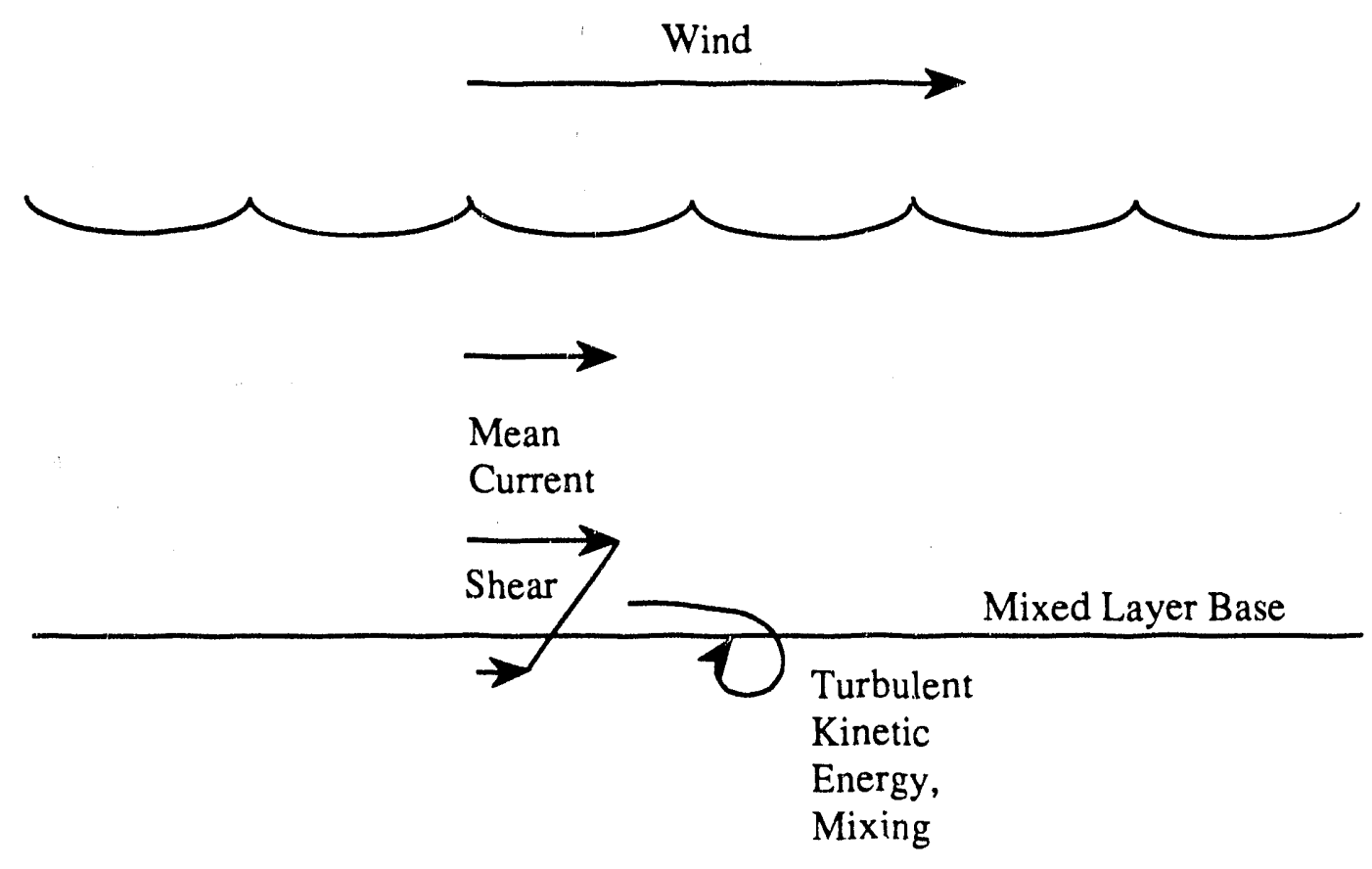

Figure 6. Diagram of the "shear instability" models.

\subsubsection{Formulation}

Mixing in a stratified fluid is governed by the gradient of velocity with depth (shear) and the density stratification (Ellison and Turner, 1959). The relevant nondimensional parameter is calculated as the ratio of these quantities (from Price et al., 1986),

$$
\mathrm{Ri}_{\mathrm{g}}=\frac{\mathrm{g} \frac{\partial \rho}{\partial z}}{\rho_{0}\left(\frac{\partial \mathrm{u}}{\partial z}\right)_{2}}
$$

and is called the gradient Richardson number.

The Richardson number used in most mixed layer models is defined somewhat differently. The mixed layer is viewed as a slab, with uniform velocity and density. Instead of the differential quantities $\partial \rho / \partial z$ and $\partial u / \partial z$, the differences $\Delta \rho / h$ and $\Delta u / h$ are 
used, where $\Delta \rho$ and $\Delta u$ are the changes in density and velocity across the mixed layer base. The length scale is the thickness of the mixed layer, $h$, rather than a scale associated with the thickness of the mixed layer base. The dimensionless number thus defined,

$$
\mathrm{Ri}_{\mathrm{b}}=\frac{\mathrm{g} \Delta \rho \mathrm{h}}{\rho_{0}(\Delta \mathrm{u})^{2}}
$$

is called the bulk Richardson number (Pollard et al., 1973; Price et al., 1986). In the shear models, mixing is ass"'med to begin when $\mathrm{Ri}_{\mathrm{b}}$ falls below a critical value, and water is entrained until $\mathrm{Ri}_{\mathrm{b}}$ reaches the critical value once again. Models based on the bulk Richardson number predict mixed layer variations quite well, and the only potentially "tunable" parameter is the critical Richardson number, which appears to be stable throughout a variety of locations and climatic conditions (Price et al., 1978; Price et al., 1986). Theoretical justification for use of the bulk, rather than the gradient, Richardson number for these models is still a matter of discussion (Pollard et al., 1973; Price et al., 1978).

The shear instability model of Price et al. (1985) uses both $\mathrm{Ri}_{b}$ and $\mathrm{Ri}_{\mathrm{g}}$ to determine mixing (Figure 7). The model was used to simulate detailed diurnal fluctuations in the mixed layer depth and current profiles from the subtropical Pacific. In the model, the heat fluxes (except penetrating solar radiation) and the wind stress are applied to the mixed layer. The bulk Richardson number at the base of the surface box is calculated, and if the shear is greater than the density stratification necessary to support it $\left(\mathrm{Ri}_{\mathrm{b}}<0.65\right)$, then the properties of the two adjacent boxes are averaged (the boxes are mixed). This process continues downward until $\mathrm{Ri}_{\mathrm{b}}>0.65$. The mixed layer is considered homogeneous for momentum and density, as it is in the bulk TKE formulations considered above. The density transition at the mixed layer base is 


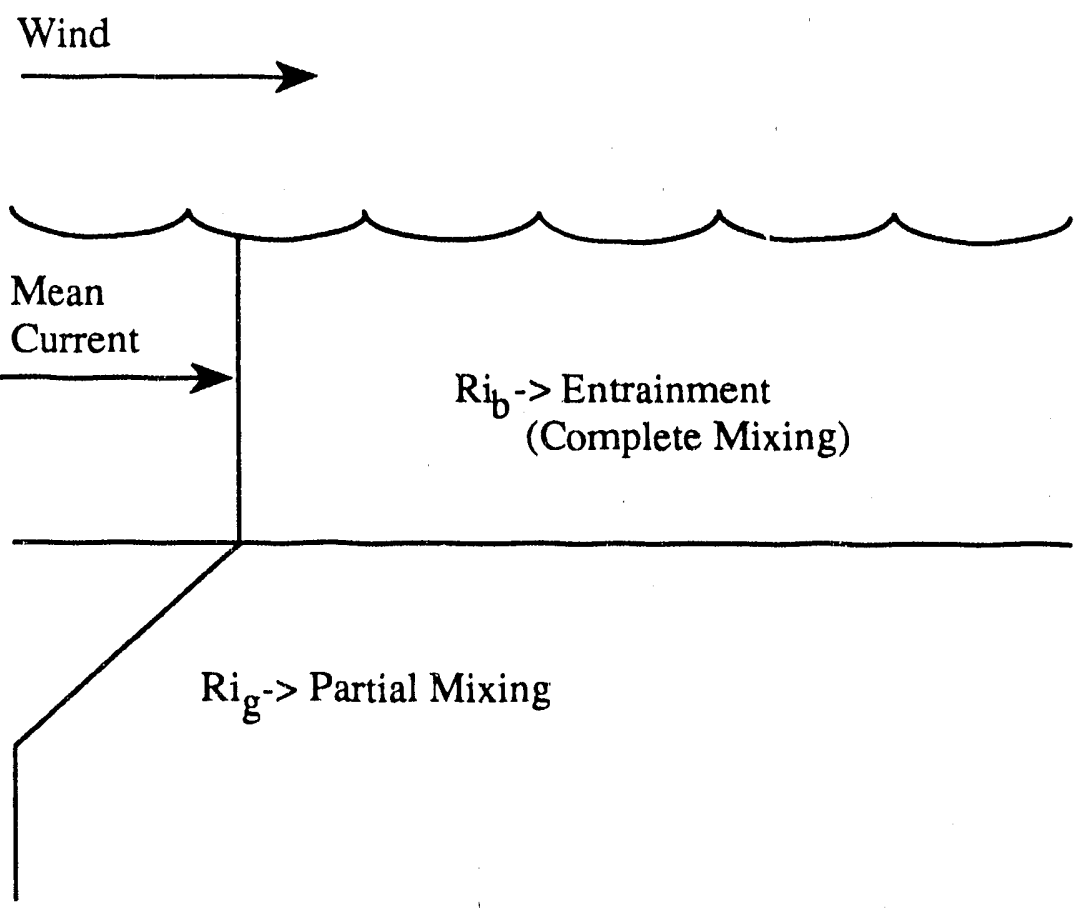

Figure 7. Diagram of the Price et al. (1985) shear instability model.

smoothed using the gradient Richardson number. If $\mathrm{Ri}_{\mathrm{g}}$ between two adjacent boxes is smaller than a critical value $\left(\mathrm{Ri}_{\mathrm{g}}<0.25\right)$, the adjacent boxes are partially mixed until the shear becomes sub-critical again, and the process is repeated until $\mathrm{Ri}_{\mathrm{g}}$ is greater than or equal to the critical value throughout the water column. Thus, there is a region of partial mixing below the completely mixed zone. The model also includes convective entrainment driven by surface cooling.

\subsubsection{Behavior}

A model in which the generation of turbulence scales with the Richardson number behaves differently from a model which scales turbulence directly with wind stress (Price et al., 1978). This is largely because of the rotation of an inertial current relative to the surface of the earth (the coriolis effect). In the presence of steady, nonrotating wind forcing, a natural limit is imposed on the current velocity by the "inertial" 
rotational frequency (the value for which varies as a function of latitude). The advantage of scaling entrainment to the current velocity, as opposed to scaling with the wind stress directly, is that the current velocity is limited by the rotational frequency, and no artificial dissipation term is required to limit the steady-state mixed layer depth. (With constant wind forcing and no dissipation term, a TKE model would entrain forever). As we have seen, the treatment of dissipation is one of the major weaknesses in the TKE model formulation.

Also, the value of the critical $\mathrm{Ri}_{\mathrm{b}}$ required to simulate oceanographic data using a shear instability mixed layer model is fairly constant throughout a range of climatic conditions (Price et al., 1978; Pollard et al., 1973; Price et al., 1986). This can be contrasted with the wind-scaling coefficient used in the TKE model, which must be tuned to simulate data from different locations or climatic regimes.

\subsection{Turbulence Closure Models}

The third family of mixed layer models is the most general, the most complicated, and the most stringently founded in the theoretical and empirical properties of fluid turbulence. These are the "turbulence closure" models, first introduced into the mainstream oceanography literature by Mellor (1973) (see also Mellor and Yamada, 1974; Mellor and Durbin, $1^{n}$ i; Mellor and Yamada, 1982). Turbulence closure models were originally constructed for use in the atmospheric boundary layer. In the oceans, Mellor's model is general enough to be applied to special cases like the equator, where the equatorial undercurrent produces regions of extremely high shear, and to a system of estuarine circulation, spanning the benthic boundary layer, the highly stratified shear flow between the saline and fresh waters, and the surface boundary layer (Oey et al, 1985).

\subsubsection{Formulation}

The physical foundation for the turbulence closure models begins with the full 
Reynold's equations for momentum and heat (from Mellor, 1973):

$$
\frac{\partial U}{\partial t}+U \cdot \nabla U+f \times U=\nabla P-g \beta \Theta+\nu \nabla^{2} U
$$

and

$$
\frac{\partial \Theta}{\partial t}+\nabla \cdot U \Theta=\alpha \nabla^{2} \Theta
$$

where $U$ is velocity, $\Theta$ is temperature, $f$ is the coriolis parameter, $P$ is pressure, $g$ is the gravitational constant, $v$ is the molecular viscosity, $\alpha$ is the thermal diffusivity, and $\beta$ is the thermal expansion coefficient. The equations for the mean flow and temperature can be found by decomposing the velocity and temperature into mean and fluctuating components and averaging:

$$
\frac{\partial \underline{U}}{\partial t}+\underline{U} \cdot \nabla \underline{U}+f \times \underline{U}=\nabla \underline{P}-g \beta \underline{\Theta}+v \nabla^{2} \underline{U}-\nabla \cdot \bar{u} u
$$

and and yamada

$$
\frac{\partial \underline{\Theta}}{\partial t}+\nabla \cdot \underline{U \Theta}=\alpha \nabla^{2} \underline{\Theta}-\nabla \cdot \bar{u} \theta
$$

The terms $\overline{\mathrm{u} u}$ and $\overline{\mathrm{u} \theta}$ represent the effect of the turbulent fluctuations on the distributions of velocity and temperature (the Reynold's stress and "eddy diffusion"). Finding analytical expressions for these terms is the problem at the heart of the turbulence closure models.

Derivation of expressions for these terms begins with these two sets of equations, and incorporates several empirical simplifying relationships based on laboratory data (the interested reader is referred to Mellor, 1973). The salient point to understand about the derivation is that the solutions contain several empirical constants, which are fit to 
laboratory data from neutral (unstratified) flows. Mellor and Yamada (1982) show the surprising result that the model, using these constants, is also able to predict laboratory data for stratified flow, flow in a pipe, and flow over a curved surface. Some of the terms in the equations also require a constant with units of length to maintain dimensional homogeneity. Mellor assumes that the length scales are all proportional to a single "mixing length scale" $(l)$. This assumption, and the derivation of a number for $l$, is considered a weak link in the turbulence closure scheme. The choice of $l$ is crucial; the levels 2 and 2.5 models (described belowi) supply eddy diffusion coefficients that scale directly to $l$.

The full version of the model is somewhat cumbersome, and some of the terms can be neglected without loss of predictive value. Mellor (1983) presents a hierarchy of closure schemes which employ increasing levels of simplification, based on the dependence of each term on the degree of anisotrophy (directional inhomogeneity) of the turbulence (the term is called "a", and is typically around $15 \%$ for the ocean surface boundary layer). The level 4 model is simplified the least, and is in general too complicated for routine oceanographic use, without any corresponding benefit in predictive value. The level 3 model neglects all terms which clearly scale with $\mathrm{a}^{2}$. There is some uncertainty to this scaling procedure. For the level 3 model the advective and diffusive terms for $\mathrm{q}^{2}$ (a synonym for $2 *$ TKE) are assumed to scale with a 1 and are left in; for the level 2 model, they are assumed to scale with $\mathrm{a}^{2}$ and are neglected. This has the importance consequence in the level 2 model of setting the diffusive flux of TKE equal to zero, so that all turbulence is dissipated locally to its generation (Niiler and Kraus, 1977).

Mellor's model of choice is called the level 2.5 model (Mellor and Yamada, 1982). Level 2.5 starts from the level 3 model but neglects the advection and diffusion of variance of the material terms like temperature and salinity (equations for 
$\overline{\mathrm{T}^{2}}$ and $\overline{\mathrm{S}^{2}}$ ). The result is the elimination of several differential equations; the savings depends on the number of scalar quantities being modeled (e.g., nutrients, $\mathrm{pCO}_{2}$ ).

The final, reduced form of the level 2.5 model adds two equations to the averaged equations of motion that would be required to model any geophysical fluid. The first describes the time and space distribution of $\mathrm{q}^{2} / 2$, the turbulent kinetic energy. Energy is added at the top as a boundary condition, advects, and diffuses according to the calculated eddy diffusion coefficient. Turbulent energy is generated by shear at the expense of mean flow. The length scale, $l$, is determined using a secrnd differential equation for the quantity $\mathrm{q}^{2} l$. The result of this formulation is that $l$, the length scale of the largest eddies, is time dependent, has memory, and is allowed to be transported. The eddy diffusion coefficient at a given time and depth is calculated as a function of $\mathrm{q}^{2}$ and l. Once the diffusion coefficient field is known, it is used for mixing the scalar quantities.

The mixing coefficient predicted by the model turns out to be a function of the local gradient Richardson number (Niiler and Kraus, 1977; Mellor and Durbin, 1975); above $\mathrm{Ri}_{\mathrm{g}}=0.23$, no mixing at all is predicted. This is similar to the Price model, in which mixing takes place until a critical $\mathrm{Ri}_{\mathrm{g}}>0.25$ is attained. The level 2.5 model has been used in a global ocean model that focuses on the surface ocean and the sea surface temperature (Rosati and Miyakoda, 1988) (see section 6.2.3.).

\subsubsection{Behavior}

The turbulence closure models are more difficult to understand in an intuitive way than the other models. Insight can be gained by comparing the behavior of the model with those of the bulk TKE and shear models described above.

One obvious distinction is the degree of mixing in the turbulence closure model mixed layer. Whereas the other formulations assume homogeneity of all properties within the mixed layer, the turbulence models predict high but finite mixing coefficients 
within this zonc. Under conditions of deep convective mixing, the "bulk" assumption (that the mixed layer is completely homogeneous in all properties) is probably inadequate (Mellor, in press), but under conditions of shallower, wind-driven mixing, the "bulk" approximation may be closer to reality than the output of the turbulence models (Martin, 1986).

The fundamental distinction between bulk and she ' $\mathrm{r}$ models presented earlier was the source of the turbulent energy for entrainment: from wind stress directly or from current shear. The main source of entrainment energy in the turbulence closure models is difficult to judge from first principles. For the primary source of turbulence to be generation at the surface, the rate of transport of turbulent energy through the mixed layer must be greater than the rate of generation of turbulence by shear at the mixed layer base. In the level 2 model, transport of turbulence does not occur; all turbulence is dissipated locally. Numerical experiments using levels 2.5 and higher have shown that the transport flux of turbulent energy from the surface zone in these models is also small relative to the generation of turbulence by shear (Klein and Coantic, 1981; Martin, 1986). Thus the turbulence closure models appear to function primarily as shear instability models.

\subsection{Mixed Layer Model Comparison}

All of the models can adequately predict observed fluctuations in the mixed layer depth in the ocean, under most conditions. There may be situations (for example, the equatorial undercurrent, or regions near a western boundary current) which are more complicated than a mid-gyre mixed layer, and these will probably be better handled by the turbulence closure scheme. On the other hand, simplicity and conservation of computer resources may be the priority, in which case a bulk TKE or shear instability model would be the model of choice. 


\subsubsection{The Stability of Empirical Parameters}

A criterion for comparison of the model formulations is the quantity and stability of the empirical parameters required for oceanic simulation. The bulk TKE models appear to be weakest in this respect, in that the coefficient which predicts TKE flux into the mixed layer based on the wind stress seems to vary as a function of climatic conditions (see section 5.1.). The empirical parameiers used by the shear instability models are the critical Richardson numbers $\mathrm{Ri}_{b}$ and $\mathrm{Ri}_{\mathrm{g}}$, which do not vary in this way (Price et al., 1978). The constants in the turbulence closure models were determined from laboratory experiments, and appear to be adequate for oceanic use (see Rosati and Miyakoda, 1988).

\subsubsection{Accuracy}

Detailed comparisons of the ability of each model to simula eceanic data are presented by Martin (1985) and Martin (1986). The latter study is an extension of the former, with the inclusion of the Price et al. (1986) model and a turbulence closure scheme other than Mellor's (Therry and Lacarrere, 1983). The conclusions are the following. First, the turbulence closure schemes are essentially Richardson numberdriven models, and the main differences among them [and the Price et al.'(1986) model] are the exact value of the critical Richardson number at which mixing commences. Second, the bulk TKE models (as represented by the model of Garwood, 1977) do not attempt to simulate partial mixing at the base of the mixed layer, as do the Price model and the turbulence closure schemes. For this reason, the bulk TKE model mixed layer base is unrealistic. Third, the turbulence models predict a greater gradient of momentum and density through the mixed layer than is observed (the data presented in Price et al., 1986); apparently, some mechanism for mixing exists (such as langmiur circulation) that is not included in the one-dimensional turbulence closure model formulation. Finally, under some circumstances, each of the models predicts mixed layer depths that deviate 
somewhat from the observed data.

\subsubsection{Computational Efficiency}

Martin (1986) also compares the computation time required by the different types of models. As written, the bulk model (Garwood, 1977) is the fastest. The Price sheardriven model is significantly slower, mainly because of calculations involved in maintenance of the partially mixed zone beneath the mixed layer (based on $\mathrm{Ri}_{\mathrm{g}}$, explained above). This model could probably be simplified or even embedded into a surface ocean box (this technique is discussed in the next section; see Adamec et al., 1981 for an embedded Richardson number-based mixed layer model). The turbulence models are the slowest, because of their complexity and the higher temporal and spatial resolution required. Turbulence models are the most suitable for use in a vectorized or parallel computer architecture, which would reduce somewhat the computation load disparity between the model types.

\subsection{Sea Ice Models}

Sea ice covers roughly $7 \%$ of the ocean surface, and its presence has a profound impact on the albedo and heat transfer properties of the ocean. The response of sea ice to global warming may provide positive feedback to the perturbations of the global system caused by fossil fuel $\mathrm{CO}_{2}$. A special application of surface ocean mixed layer models is required for the treatment of sea ice, especially in the marginal ice zone where seawater is exposed to the surface and is affected both by heat exchange with the atmosphere and by the presence and dynamics of sea ice. There are two basic types of sea ice models: the thermodynamic models, which apply mostly to areas of high fractional coverage of the ocean surface with sea ice; and dynamic models, which describe the interplay between the ice and the ocean mixed iayer physics in the marginal ice zone. 


\subsubsection{Ice-Only Models}

\subsubsection{Thermodynamic Models}

The "thermodynamic models".(Maykut and Untersteiner, 1971; Semtner, 1976) describe the change in sea ice thickness with time, in areas of high fractional coverage of the ocean surface with sea ice. In the Semtner (1976) model, ice growth begins when the surface heat flux to the atmosphere exceeds a critical value. The growth of the ice thickness is governed by the radiative and conductive heat fluxes to the ice from the atmosphere and the water below. Temperature profiles within the ice and in the snow layer above are calculated numerically based on the heat equation (from Semtner, 1976):

$$
\rho_{\text {ice }} c \frac{\partial T}{\partial t}=k \frac{\partial^{2} T}{\partial z^{2}}
$$

where $\rho_{\text {ice }}$ is ice density, $c$ is heat capacity, and $k$ is thermal diffusivity. This equation is coupled to a similar one for the snow layer on top of the ice.

Radiation contributes heat to the ice itself (if there is no snow cover) and to the water below (if the ice is thin enough). When sea ice freezes, it traps pockets of brine, the freezing points of which are depressed by dissolved salt. The brine pockets freeze if enough heat is removed from the ice, and enlarge in response to radiative heating, remaining trapped in the ice. The state of the brine pockets (size, salinity, and temperature) is significant to the overall heat budget for the ice and is therefore simulated in thermodynamic ice models.

Semtner (1976) presents two algorithms based on simplifications of the model of Maykut and Untersteiner (1971) and shows that either one can simulate observed data. The model of Semtner (1976) was incorporated into an areal simulation by Washington et al. (1976). 


\subsubsection{Marginal Ice Zone Models}

Much of the high-latitude ocean influenced by the presence of sea ice is not covered completely by ice. In the marginal ice zone, ice breaks free from the pack and drifts into warmer waters. Modeling of ice behavior in this situation is very different from the thermodynamic models described above. In the formulation by Roed (1984) the thickness of the ice is prescribed by the model, and the areal coverage is predicted. When ice forms in the "leads" (openings in the ice pack) it is presumed to break up by the action of the ice floes and to contribute to their lateral, rather than vertical, growth. The heat fluxes from the leads are very different from those from the ice-covered regions. The model is able to predict transient freezing and melting in response to atmospheric forcing and also steady-state solutions for which the heat flux into the mixed layer from the deep ocean balances the sea-air heat flux. This ice model was coupled to a bulk mixed layer model by Houssais (1988).

\subsubsection{Coupled Sea Ice / Mixed Layer Dynamics Models}

The thermodynamic models for ice formation and melting take the thickness of the ocean mixed layer as a boundary condition to the model, although it is generally acknowledged that the freezing and melting of ice has a profound impact on the heat and density structure of the mixed layer. As such, modeling of sea ice can be improved by the addition of : mixed layer dynamical model. Several workers have coupled sea ice models with 1-D bulk TKE mixed layer formulations (Pollard et al., 1983; Houssais, 1988; Fichefet and Gaspar, 1988).

However, the best results seem to have come from coupling ice models with the turbulence closure mixed layer model (1-D examples include Mellor et al., 1986 and Ikeda, 1986). At the onset of ice meiting, the addition of cold fresh water at the sea surface stratifies the surface ocean. The water above the rosuiting kalocline ccols until

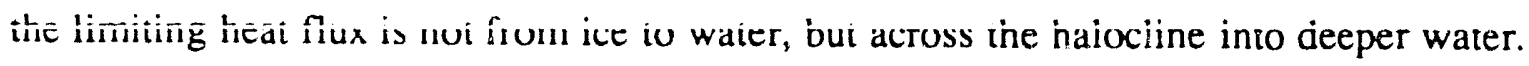


Wind-driven currents within a shallow meltwater mixed layer are faster than if the mornentum were mixed into a thick mixed layer, and therefore the coupled model predicts that melting ice at the ice edge should drift more quickly than the interior ice (Mellor et al., 1986). This prediction is consistent with measurements of ice drift rates in the winter Bering Sea (Martin et al., 1983). The parameterization of the heat fluxes was improved by Mellor and Kantha (1989), and these types of models were used in two dimensions (a meridional plane) by Ikeda (1989) and Kantha and Mellor (1989) to predict the dynamics of sea ice in the marginal ice zone. 


\section{The Mixed Layer in Ocean Circulation Models.}

The processes occurring within and regulated by the mixed layer (e.g., the nutrient flux into the photic zone or the rate of exchange of water across the thermocline) are crucial to modeling the oceanic uptake of fossil-fuel $\mathrm{CO}_{2}$ with mechanistic understanding and predictive value. Modeling of the global ocean circulation is at present compromised by finite computational resources. The benefits of using an increasingly complex simulation (for example, including a powerful mixed layer model) are balanced by limitation of the number of model runs that can be done for sensitivity studies. Thus, a mixed layer model that may be the most accurate for a single location may be too time- or memory-intensive to be the best choice for an oceanic general circulation model (OGCM).

However, some regions of the world's oceans will not be well simulated by some of the simpler mixed layer models. The equator is one such example, where inertial currents do not rotate, and where upwelling driven by large-scale dynamics plays a role in determining the mixed layer depth (the assumption of one-dimensional forcing is not adequate). Western boundary currents may be another. Also, the "bulk TKE" and the "shear" mixed layer models may not simulate winter deep convective mixing in high latitudes, since it is unlikely that the entire "mixed" layer (which may be $>1000$ meters deep) will be completely homogeneous in its physical and chemical properties. The formation and melting of sea ice imposes unusual conditions on the surface density structure.

\subsection{Overview}

An annotated list of GCM publications is included in Appendix B, and so only a few representative examples will be discussed here. The models derive from two sources: in this county, they are generally descended from the model of Bryan et al. (1975), Bryan and Lewis (1979), and Cox (1970) at the Geophysical Fluid Dynamics 
Laboratory in Princeton. A model of different genesis is running at the Max Plank Gesellschaft in Hamburg (Maier-Reimer and Hasselman, 1987).

\subsubsection{Calculated Heat Fluxes vs. SST-Restoring Models.}

When comparing the various ocean circulation model studies, we must pay attention to a fundamental distinction. Some of the studies predict the sea surface temperature and heat fluxes from the atmosphere using formulas similar to equations $10-$ 15 above, while others force the model SST toward the observations using some relaxation time constant. OGCM's which include modeling of nutrients and organic matter can also be driven by an analogous "nutrient restoring" method, where the surface nutrients are driven towards the observed values (Sarmiento et al., 1989; Najjar, 1990).

\subsubsection{Simulating Free and Forced Convection.}

There are two processes which drive the formation of a surface mixed layer: free convection resulting from surface cooling, and forced convection driven by the wind stress. The former process is responsible for the deep mixing at high latitudes which ventilates the thermocline and deeper waters. The mixing of water parcels which have become unstable due to cooling is universally represented in the two families of ocean general circulation models. The process of wind-driven mixing is generally on a smaller depth scale, and is included or omitted, depending on the resolution of the model.

\subsubsection{High Spatial Resolution vs. Embedded Models.}

The most straightforward way of incorporating the detail near the ocean surface is to allocate lots of grid points near the surface. The high-resolution approach is best able to simulate near-surface gradients in density, temperature, and velocity. The disadvantage of this method is that resolution of the deeper ocean suffers, because of computational limitations (e.g., Rosati and Miyakoda, 1988). Near-surface resolution may be compromised for the sake of the deep-water circulation (eg. the models of Bryan, 1975; Bryan and Lewis, 1979; both of which have one grid point at $25 \mathrm{~m}$ depth and one at 
$85 \mathrm{~m}$ depth).

The other method of including a mixed layer is to "embed" it into the upper ocean as a box of variable thickness (eg., Adamec et al., 1981; the model of Han presented in Sherwood and Downing, 1988). Temperature, salinity, velocity, etc. are predicted in the mixed layer just as for a box of fixed thickness in the ocean interior, and the code also tracks the thickness of the mixed layer and the density "jump" across the base of the mixed layer. In this way, the mixed layer thickness can vary continuously rather than being "quantized" at grid placements. This scheme uses relatively little variable storage and so does not compromise the rest of the simulation.

\subsection{Examples of the Mixed Layer in Circulation Models}

Each of the three types of mixed layer formulation (bulk wind-stress models, Richardson-number models, and turbulence closure models) have been implemented in ocean circulation models.

\subsubsection{Bulk Models}

The Princeton-GFDL ocean circulation model allows wind-driven mixing based on the bulk model of Kraus and Turner (1967). The model has gridpoints at 25 and $85 \mathrm{~m}$ depth, so the resolution of this mixed layer is limited. Also, the model of Han (as described in Sherwood and Downing, 1988) has an embedded mixed layer which scales entrainment with the wind stress.

\subsubsection{Shear Models}

Richardson number-driven mixing has also been explored for use in modeling ocean circulation. The Ri-based mixing formulation of Pacanowski and Philander (1981) was developed to simulate the equatorial Pacific, where the structure of the equatorial counter-current in particular is very sensitive to turbulent mixing rates. Richardson number-based mixing was used by Adamec et al. (1981) in their construction of an embedded mixed layer formulation intended for use in OGCM's. 


\subsubsection{Turbulence Closure Models}

The turbulence closure scheme was used in the model of Rosati and Miyakoda (1988). The model is implemented with 12 layers, 8 of which are in the top 250 meters. The deep water circulation is only represented crudely, and the model could only be used for short simulations $[<50-100$ years (Rosati, personal communication)]. Although the turbulence scheme can in principal calculate the diffusion coefficient throughout the entire water columin, below the wind-mixed zone mixing occurs as a result of internal waves, salt fingers, or other mechanisms (Gregg, 1987) not represented by the turbulence closure model. A minimum, "background" diffusivity is imposed to represent these processes. Rosati evaluates th: sensitivity of the SST simulations to the mixed layer model and finds that the predictions using the turbulence closure scheme are much better than simulations using a constant diffusivity. 


\section{Summary}

Sea surface $\mathrm{pCO}_{2}$ is driven by a variety of physical, chemical, and biological oceanographic processes. The $\mathrm{CO}_{2}$ concentration is controlled by the carbonate buffer sysiem, which tends to maintain the concentration of $\mathrm{CO}_{2}$ at a constant level in spite of addition or removal of $\mathrm{CO}_{2}$ by biological or physical processes. The buffer system provides an effective reservoir for $\mathrm{CO}_{2}$ in seawater that is 10 times larger than it would be for an unbuffered gas. The solubility of $\mathrm{CO}_{2}$ in seawater decreases with tempcrature (in other words, the $\mathrm{pCO}_{2}$ increases).

The $\mathrm{pCO}_{2}$ at the sea surface is lower than it is at depth, because of the export of carbon from the surface ocean as sinking biogenic particles. Biological production is limited in most parts of the ocean by nutrient availability; thus predicting surface ocean $\mathrm{pCO}_{2}$ requires modeling nutrient transport and recycling in the upper ocean. Neither of these processes is well understood. Prediction of atmospheric $\mathrm{pCO}_{2}$ will also require better understanding of the limits to phytoplankton growth in the high-latitude oceans, where dissolved nutrients appear to be available in abundance in the euphotic zone.

Because a primary driver for many of the processes which control surface ocean $\mathrm{pCO}_{2}$ is the seasonal cycle of the depth of the surface mixed layer, this report reviews the available numerical models that predict the depth of the mixed layer. Three families of mixed layer models have been developed. "Integrated turbulent kinetic energy" models scale turbulence generation to the wind stress and parameterize dissipation as a sink. Excess TKE is transformed to potential energy by mixing denser water up into the surface mixed layer. The weaknesses of this formulation are the necessity of "tunable" constants and uncertainty about the dissipation of turbulence. "Shear instability" models assume that the wind generates mean currents rather than turbulent velocity fluctuations; entrainment is parameterized based on the current shear at the base of the mixed layer relative to the density stratification. This type of model has the advantage of generality; 
the same model, with the same values for the required empirical constants, is able to simulate a wide range of climatic conditions. The "turbulence closure" models are the most general and the most complicated of the three types. Analysis of the behavior of turbulence closure models (Martin, 1986) reveals that these models are essentially shear instability models when applied to the surface ocean; with small variations in the effective critical Richardson number at which mixing begins. The bulk TKE models are the most computationally efficient; the turbulence closure models are the least.

All three types of mixed layer model have been used in global circulation models, and these examples are reviewed. Large-scale simulation of the global surface ocean may be compromised hy finite computational resources and inadequate atmospheric forcing data. One strategy for reducing memory requirements is to "embed" the model mixed layer into a box of variable thickness at the surface. Instead of calculating the heat fluxes based on meteorological data, some models restore the sea surface temperature toward observed values, 


\section{Acknowledgements}

I wish to thank John Downing at Battelle Marine Sciences Laboratory for guidance and commentwity, Steve Emerson, Jim Price, Tom Powell, Scott Doney, and Molly Knox for reviewing the manuscript, and Andy Plymale for editorial comments. This work was supported by the U.S. Department of Energy under contract DE-AC0676RLO 1830 with the Battelle Memorial Institute. 


\section{Citations}

Adamec D., Elsberry R.L., Garwood R.W., and Haney R.L. (1981) An embedded mixedlayer -- ocean circulation model. Dyn. Atmos. Oceans 6, 69-96.

Broecker W.S. and Peng T.H. (1982) Tracers in the sea. Eldigio Press, Palisades, NY, $690 \mathrm{pp}$.

Bryan K., Manabe S., and Pacanowski R.C. (1975) A global ocean-atmospheric climate model. Part II. The oceanic circulation. J. Phys. Ocean. 5, 1, 30-46.

Bryan, K., and L.J. Lewis, A water mass model of the world ocean (1979) J. Geophys. Res., 84 (C5), 2503-2517.

Bryan K. (1982) Seasonal variation in meridional overturning and poleward heat transport in the Atlantic and Pacific Oceans: a model study. J. Mar. Res. 40, suppl., 39-53.

Cox, M.D., A mathematical model of the Indian Ocean (1970) Deep Sea Res., 17, 47-75.

Davis R.E., deSzoeke R., and Niiler P. (1981a) Variability in the upper ocean during MILE. Part I: The heat and momentum balances. Deep Sea Res. 28A(12), 14271451.

Davis R.E., dsSzoeke R., and Niiler P. (1981b) Variability in the lipper ocean during MILE. Part II: Modeling the mixed layer response. Deep Sea Res. 28A(12), 1453-1475.

Denman K.L. and Gargett A.E. (1988) Multiple thermoclines are barriers to vertical exchange in the subarctic Pacific during SUPER, May 1984. J. Mar. Res. 46, 77 103.

Dugdale R.C. and Goering J.J. (1967) Uptake of new and regenerated forms of nitrc gen in primary productivity. Limnol. Oceanogr. 12, 196-207.

Ellison T.H., and Turner J.S. (1959) Turbulent entrainment in stratified flows. J. Fluid Mech. 6, 423-448.

Elsberry R.L., Friam T.S., and Trapnell R.N.Jr. (1976) A mixed layer model of the oceanic thermal response to hurricanes. J. Geophys. Res. 81(6), 1153-1162.

Emerson S. (1987) Seasonal oxygen cycles and biological new production in surface waters of the subarctic Pacific Ocean. J. Geophys. Res. 92(C6), 6535-6544. 
Emerson S., Quay, P, Stump, C., Wilbur D., and Knox M. (in preparation) Geochemical tracers of biological processes in the upper ocean I: $\mathrm{O}_{2}, \mathrm{Ar}, \mathrm{N}_{2}$, and ${ }^{22} \mathrm{Rn}$.

Enfield D.B. (1989) El NiDo, past and present. Reviews of Geophysics, 27, 159-187.

Eppley R.W., and Peterson B.J. (1979) Particulate organic matter flux and planktonic new production in the deep ocean. Nature 282, 677-680.

Evans G.T., and Parslow J.S. (1985) A model of annual plankton cycles. Biol. Oceinogr. 3, 327-347.

Fenchel T (1988) Marine plankton food chains. Ann. Rev. Exol. Syst. 19, 19-38.

Fichefet T., and Gaspar P. (1988) A model study of upper ocean sea-ice interactions. J. Phys. Ocean. 18, 131-195.

Fitzwater S.E., Knaur G.A., and Martin J.H. (1982) Metal contamination and its effect on primary production measurements. Limnol. Oceanogr. 27, 544-551.

Frost B.W. (1987) Grazing control of phytoplankton stock in the open subarctic Pacific Ocean : a model assessing the role of mesozooplankton, particularly the large calanoid copepod Neocalanus spp. Mar. Ecol. Prog. Ser. 39, 49-68.

Frouin R., Linger D.W., Gautier C., Baker K.S., and Smith R.C. (1989) A simple analytical formula to compute clear shy total and photosynthetically available solar irradiance at the ocean surface. J. Geophys. Res. 94 (C7), 9731-9743.

Gargett A.E., Sanford T.B., and Osborn T.R. (1979) Surface mixing layers in the Sargasso Sea. J. Phys. Ocean. 9, 1090-1111.

Garwood R.W. (1977) An ocean mixed layer model capable of simulating cyclic states. J. Phys. Ocean. 7, 455-468.

Gaspar P. (1988) Modeling the seasonal cycle of the upper ocean. J. Phys. Ocean. 18, $161-180$.

Gill A.E. (1982) Atmosphere-Ocean Dynamics, Academic Press, Orlando, 662.

Gill A.E., and Turner J.S. (1976) A comparison of seasonal thermocline models with observation. Deep Sea Res. 23, 391-401.

Gregg M.C. (1987) Diapycnal mixing in the thermocline: a review. J. Geophys. Res. 92, 5249-5286. 
Hamilton J.M., Lewis M.R., and Ruddick B.R. (1989) Vertical fluxes of nitrate associated with salt fingers in the world's oceans. J. Geophys. Res. 94 (C2), 2137 2147.

Harrison W.G. (1983) In Nitrogen in the Marine Environment(ed E.J. Carpenter, and D.G. Capone), Academic Press.

Hayward T.L. (1987) The nutrient distribution and primary production in the central North Pacific. Deep Sea Res. 34(9), 1593-1627.

Houssais M.N. (1988) Testing a coupled ice-mixed-layer model under subarctic conditions. J. Phys, Ocean. 18, 196-210.

Ikeda M. (1986) A mixed layer beneath melting sea ice in the marginal ice zone using a one-dimensional turbulent closure model. J. Geophys. Res. 91 (C4), 5054-5060.

Ikeda M. (1989) A coupled ice-ocean mixed layer model of the marginal ice zone responding to wind forcing. J. Geophys. Res. 94 (C7), 9699-9709.

Jenkins W.J. (1982) Oxygen utilization rates in North Atlantic subtropical gyre and primary production in oligotrophic systems. Nature 300, 246-248.

Jenkins W.J., and Goldman J.C. (1985) Seasonal oxygen cycling and primary production in the Sargasso Sea. J. Mar. Res. 43, 465-491.

Jerlov N.G. (1976) Marine Optics, Elsevier, Amsterdam.

Johnson K.M., King, A.E., and Sieburth J.McN. (1985) Coulometric $\mathrm{TCO}_{2}$ analyses for marine studies: an introduction. Mar. Chem. 16, 61-82.

Kantha L.H., and Mellor G.L. (1989) A two-dimensional coupled ice-ocean model of the Bering Sea marginal ice zone. J. Geophys. Res. 94 (C8), 10921-936.

Kim J-.W. (1976) A generalized bulk model of the oceanic mixed layer. J. Phys. Ocean. 6, 686-695.

Klein P. and Coantic M. (1981) A numerical study of turbulent processes in the marine upper layers. J. Phys. Ocean. 11, 849-863.

Kraus E.B., and Turner J.S. (1967) A one-dimensional model of the seasonal thermocline II. The general theory and its consequences. Tellus 19, 98-105.

Lewis M.R. Harrison W.G., Oakey N.S., Herbert D., and Platt, T. (1986) Vertical nitrate fluxes in the oligotrophic ocean. Science, 234,870-872. 
Liss P.S., and Merlivat L. (1986) Air-sea gas exchange rates: introduction and systhesis, in The role of air-sea exchange in geochemical cycling (Buat-Menard, ed.) D. Reidel.

Lorius C., Jouzel J., Raynaud D., Hansen J., and Le Treut H. (1990) The ice-core record: climate sensitivity and future greenhouse warming. Nature, 347, 139-145.

Luyten J.R., Pedlosky J., and Stommel H. (1983) The ventilated thermocline. J. Phys. Ocean. 13, 292-309.

Maier-Reimer E., and Hasselmann K. (1987) Transport and storage of CO2 in the ocean - an inorganic' ocean-circulation carbon cycle model. Climate Dynamics 2, 63-90.

Marra J., and Heinemann K. (1984) A comparison between noncontaminating and conventional incubation proceedures in primary production measurements. Limnol. Oceanogr. 29, 389-392.

Martin J.H., Knauer G.A., Karl D.M., and Broerıkow W.M. (1987) VERTEX: carbon cycling in the northeast Pacific. Deep Sea Res. 34(2), 267-285.

Martin J.H. and Fitzwater S.E. (1988) Iron deficiency limits phytoplankton growth in the north-east Pacific subarctic. Nature 331, $341-343$.

Martin J.H., and Gordon R.M. (1988) Northeast Pacific iron distributions in relation to phytoplankton productivity. Deep Sea Res. 35, 177-196.

Martin P.J. (1985) Simulation of the mixed layer at OWS November and Papa with several models. J. Geophys. Res. 90(C1), 903-916.

Martin P.J. (1986) Testing and comparison of several mixed-layer models. Naval Ocean Research and Development Activity Tech Rep 143.

Martin S., Kauffmann P., and Parkinson C. (1983) The movement and decay of ice edge bands in the winter Bering Sea. J. Geophys. Res. 88 (C5), 2803-2812.

Maykut G.A., and Untersteiner N. (1971) Some results from a time-dependent, thermodynamic model of sea ice. J. Geophys. Res. 76, 1550-1575.

Mellor G.L. (1973) Analytic prediction of the properties of stratified planetary surface layers. J. Atm. Sci. 30, 1061-1069.

Mellor G.L., and Yamada T. (1974) A hierarchy of turbulence closure models for planetary boundary layers. J. Atmos. Sci. 31, 1791-1806.

Mellor G.L., and Durbin P.A. (1975) The structure and dynamics of the ocean surface mixed layer. J. Phys. Ocean. 5, 718-728. 
Mellor G.L., and Yamada T. (1982) Development of turbulence closure model for geophysical fluid problems. Rev. Geophys. Space Phys. 20(4), 851-875.

Mellor G.L., McPhee M.G., and Steele M. (1986) Ice-seawater turbulent boundary layer interaction with melting or freezing. J. Phys. Ocean. 18, 1829-1846.

Mellor G.L. (in press) Retrospective on oceanic boundary layer modeling and second moment closure. Manuscript, submitted.

Mellor G.L., and Kantha L. (1989) An ice-ocean coupled model. J. Geophys. Res. 94 (C8), 10937-955.

Mitchell J.F.B., Senior C.A., and Ingram W.J. (1989) $\mathrm{CO}_{2}$ and climate: a missing feedback? Nature 341, 132-134.

Morel A. (1988) Optical modeling of the upper ocean in relation to its biogenous matter content (Case I waters). J. Geophys. Res, 93 (C9), 10749-68.

Musgrave D.L., Chou J., and Jenkins W.J. (1989) Application of a model of upper-ocean physics for studying seasonal cycles of oxygen. J. Geophys. Res. in press,

Najjar R.G. (1990) Simulations of the phosphorus and oxygen cycles in the world ocean using a general circulation model. Ph.D. dissertation, Princeton University.

Niiler P.P., and Kraus E.B. (1977) One-dimensional models of the upper ocean. In Modelling and Prediction of the Upper Layers of the Ocean(ed E.B. Kraus), pp. 143-172. Pergammon Press.

Oey L.-Y., Mellor G.L. and Hires R.I. (1985) A three-dimensional simulation of the Hudson-Raritan estuary. Part I: description of the model and model simulations. J. Phys. Oceanogr. 15, 1676-1692.

Pacanowski R.C., and Philander S.G.H. (1981) Parameterization of vertical mixing in numerical models of tropical oceans. J. Phys. Ocean. 11, 1443-1451.

Parsons T.R., Takahashi M., and Hargrave B. (1984) Biological Oceanographic Processes, 3rd Edition. Pergammon Press, Oxford. 330 pp.

Peng T-.H., Takahashi T., Broecker W.S., and Olafsson J. (1987) Seasonal variability of carbon dioxide, nutrients, and oxygen in the northern North Atlantic surface water: observations and a model. Tellus 39B, 439-458.

Platt T., Harrison W.G., Lewis M.R., Li W.K.W., Sathyendranath S., Smith R.E., and Vezina A.F. (1989) Biological production of the oceans: the case for a consensus. Mar. Ecol. Prog. Ser. 52, 77-88. 
Pollard R.T., Rhines P.B., and Thompson R.O.R.Y. (1973) The deepening of the windmixed layer. Geophys. Fluid Dyn. 3, 381-404.

Pollard D., Bateen M.L., and Han Y.J. (1983) Development of a simple upper-ocean and sea-ice model. J. Phys. Ocean. 13, 754-768.

Price I.F., Mooers C.N.K., and Van Leer. J.C. (1978) Observations and simulation of storm-induced mixed-layer deepening. J. Phys. Ocean. 8, 582-599.

Price J.F., Weller R.A., and Pinkle R. (1986) Diurnal cycling: observations and models of the upper ocean response to diurnal heating, cooling and wind mixing. J. Geophys. Res. 91(C7), 8411-8427.

Reuter J.G., and Ades D.R. The role of iron nutrition in photosynthesis and nitrogen assimilation in Scendesmus Quadricuada (Chlorophyceae). J. Phycol. 23, 452457.

Roed L.P. (1984) A thermodynamic coupled ice-ocean model of the marginal ice zone. J. Phys. Ocesn. 14, 1921-1929.

Rosati A., and Miyakoda K. (1988) A gereral circulation model for upper ocean simulation. J. Phys. Ucean. 18, 1601-1626.

Sarmiento J.L., Toggweiler J.R., and Najjar R. (1988) Ocean carbon-cycle dynamics and atmospheric $\mathrm{pCO}_{2}$. Phil. Trans. R. Soc. Lond. A 325, 3-21.

Sarmiento J.L., Fasham M.J.R., Siegenthaler U., Najjar R., and Toggweiler J.R. (1989) Models of chemical cycling in the oceans: progres' report II. Ocean Tracers Laboratory Technical Report \# 6

Sathyendranath S., and Platt T. (1988) The spectral irradiance field at the surface and in the interior of the ocean: a model for applications in oceanography and remote sensing. J. Geophys. Res. 93 (C8), 9207-9280.Sherwood C.R., and Downing J.P. Ocean general circulation models: report on proceedings of a meeting of ocean and climate modelers. DOE report

Seager R., Zebiak S.E., and Cane M.A. (1988) A model of the tropical Pacific sea surface temperature climatology. J. Geophys. Res. 93, 1265-1280.

Semtner A.J. (1976) A model for the thermodynamic growth of sea ice in numerical investigations of climate. J. Phys. Ocean. 6, 379-389.

Sherwood C.R. and Downing J.P. (1988) Ocean general circulation models: report on proceedings of a meeting of ocean and climate modelers. Department of Energy, Sequim, Wa.., :6 pr. 
Spitzer W.S., and Jenkins W.J. (1989) Rates of vertical mixing, gas exchange, and new production: estimates from seasonal gas cycles in the upper ocean near Bermuda. J. Mar. Res. 47, 169-196.

Spitzer W.S., and Jenkins W.J. (1990) Nutrient injection into the euphotic zone near Bermuda. EOS 71, 154 (Abstract).

Stevenson J.W. (1979) On the effect of dissipation on seasonal thermocline models. J. Phys. Ocean. 9, 57-64.

Stumm W. and Morgan J.J. (1981) Aquatic Chemistry: an Introduction Emphasizing Chemical Equilibria in Natural Waters, second edition. Johin Wiley and Sons, New York.

Suzuki Y., Sugimura Y., and Itoh T. (1985) A catalytic oxidation method for the determination of total nitrogen dissolved in seawater. Mar. Chem. 24, 105-131.

Takahashi T., Chipman D., Schechtman N., Goddard J., and Wannikof R. (1982) Measurements of the partial pressure of $\mathrm{CO}_{2}$ in discreet water samples during the North Atlantic Expedition, the Transient Tracers of Oceans Project. Technical Report to NSF, Lamont-Doherty Geol. Obs., Palisades, NY, 269 pages.

Therry G., and Lacarrere P. (1983) Improrning the eudy kinetic energy model for planteary boundary layer descriptisn. Boundary Layer Meteorology, 25, 63-88.

Toggweiler J.R. (1989) Is the downward ciissolved organic matter (DOM) flux important in carbon transport? In Productivity of the Ocean: Past and Present(ed W.H. Berger, V.S. Smetacek, and G. Wefer), pp. 65-83. John Wiley and Sons Limited.

Washington W.M., Semtner A.J., Parkinson C., and Morrison L. (1976) On the development of a seasonal change sea-ice model. J. Phys. Ocean. 6, 679-685.

Weare B.C., Strub P.T., and Samuel M.D. (1981) Annual mean surface heat fluxes in the tropical Pacific Ocean. J. Phys. Oceanogr. 11, 705-717.

Welschmeyer, N. (1990) Organic carbon and nitrogen flux: subarctic Pacific versus Sargasso Sea. Nature, submitted.

Wheeler P.A., and Kokkinakis S.A. (submitted) Inhibition of nitrate uptake by submicromolar ammonium in the ocean subarctic Pacific: ammonium recycling limits new production. Limnol. Oceanogr.

Wigley T.M.L. (1989) Possible climate change due to $\mathrm{SO}_{2}$ - derived cloud condensation nuclei. Nature 339, 365-367. 
Woods J.D., and Barkmann W. (1986) The response of the upper ocean to solar heating. I: The mixed layer. Quart. J. Roy. Met. Soc. 112, 1-42.

Wu J. (1982) Wind-stress over sea surface from breeze to hurricane. J. Geophys. Res. 87 (C12), 9704-9706.

Volk T. and Liu Z. (1988) Controls of $\mathrm{CO}_{2}$ sources and sinks in the earth scale surface ocean: temperature and nutrients. Global Biogeochemical Cycles 2 (2), 73-89. 


\section{Appendix A. Annotated Bibliography of Mixed Layer Models.}

\section{A.1 Bulk Wind-Stress Driven Models.}

Kraus, E.B., and J.S. Turner, A one-dimensional model of the seasonal thermocline II. The general theory and its consequences (1967) Tellus, 19, 98-105. The classic bulk TKE mixed layer model, discussed in text. Later improvements were made in the dissipation term (many authors).

Denman, K.L., A time-dependent model of the upper ocean (1973) J. Phys. Ocean., 3, 173-184. A somewhat more rigorous derivation and explanation of the $\mathrm{KT}$ model.

Alexander, R.C., and J-.W. Kim, Diagnostic model study of mixed-layer depths in the summer North Pacific (1976) J. Phys. Ocean., 6, 293-298. They present a new parameterization of the dissipation term, to fit data in the North Pacific.

Elsberry, R.L., T.S. Friam, and R.N.Jr. Trapnell, A mixed layer model of the oceanic thermal response to hurricanes (1976) J. Geophys. Res., 81(6), 1153-1162. They use a KT type model, with a new parameterization of the dissipation term.

Gill, A.E., and I.S. Turner, A comparison of scasonal thermocline models with observation (1976) Deep Sea Res., 23, 391-401.

Kim, J-.W., A generalized bulk model of the oceanic mixed layer (1976) J. Phys. Ocean., 6, 686-695.

Garwood, R.W. An ocean mixed layer model capable of simulating cyclic states (1977) J. Phys. Ocean., 7, 455-468. A hybrid bulk model which scales entrainment with wind stress and with current shear. He concludes that Ri mixing is unimportant.

Niiler, P.P., and E.B. Kraus. One-dimensional models of the upper ocean (1977) in Modelling and Prediction of the Upper Layers of the Ocean, edited by E.B. Kraus, pp. 143-172. An excellent review of the bulk mixed layer models, and also the turbulence closure models.

Stevenson, J.W., On the effect of dissipation on seasonal thermocline models (1979) J. Phys. Ocean., 9, 57-64. Extensive review of the issue of dissipation in the winddriven bulk mixed layer models.

Davis, R.E., R. dsSzoeke, and P. Niiler, Variability in the upper ocean during MILE Part II: Modeling the mixed layer response (1981) Deep Sea Res., 28A(12), 1453 1475. A hybrid model, with turbulence generation both by wind stress scaling and by current shear. They find that both types of turbulence production, shear and wind, are needed to simulate their data from part I. of the set, but are dubious

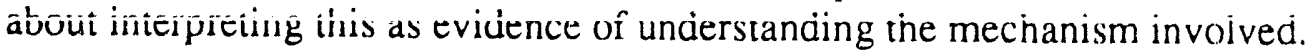


Gaspar, P., Modeling the seasonal cycle of the upper ocean (1988) J. Phys. Ocean., 18, 161-180. A bulk wind-stress scaled mixed layer model with an improved dissipation term. 


\section{A.2 Richardson-Number Based Formulations}

Pollard, R.T., P.B. Rhines, and R.O.R.Y. Thompson, The deepening of the wind-mixed layer (1973) Geophys. Fluid Dyn., 3, 381-404. Theoretical discussion of entrainment based on current shear as opposed to direct wind stress scaling. Several hypothetical explanations for the use of $\mathrm{Ri}_{b}$ are offered. See also deSzoeke and Rhines, 1976.

deSzoeke, R.A., and P.B. Rhines, Asymptotic regimes in mixed-layer deepening (1976) J. Mar. Res., 34, 111-116. Mathematical argument that the wind stress ought to be the immediate source of turbulence only for the initial transient response of the mixed layer to sudden wind, then the shear turbulence production ought to take over.

Garwond, R.W. An ocean mixed layer model capable of simulating cyclic states (1977) J. Phys. Ocean., 7, 455-468. A hybrid bulk model which scales entrainment with wind stress and with current shear. He concludes that Ri mixing is unimportant.

Price, J.F., C.N.K. Mooers, and Van Leer J.C. Observations and simulation of storminduced mixed-layer deepening (1978) J. Phys. Ocean., 8, 582-599. Compares the stability of the empirical constants required for bulk TKE models and for shear instability models. They find that the constants needed for wind-stress scaling of entrainment change under different conditions, whereas for the Ri scaling, they are constant over a range of climatic conditions.

Adamec D., Elsberry R.L., Garwood R.W., and Haney R.L., An embedded mixed-layer -- ocean circulation model (1981) Dyn. Atmos. Oceans 6, 69-96. An embedded formulation of a bulk mixed layer model, using the Richardson number dependent mixing.

Davis, R.E., R. dsSzoeke, and P. Niiler, Variability in the upper ocean during MILE. Part II: Modeling the mixed layer response (1981) Deep Sea Res., 28A(12), 14531475. A hybrid model, with turbulence generation both by wind stress scaling and by current shear. They find that both types of turbulence production, shear and wind, are needed to simulate their data from part I. of the set, but are dubious about interpreting this as evidence of understanding the mechanism involved.

Pacanowski, R.C., and S.G.H. Philander, Parameterization of vertical mixing in numerical models of tropical oceans (1981) J. Phys. Ocean., 11, 1443-1451. Outlines a $\mathrm{Ri}_{\mathrm{g}}$-dependent eddy mixing formulation, where diffusivity varies continuously with $\mathrm{Ri}$, rather than being turned on at a critical $\mathrm{Ri}$, as in the Price formulation and others. 
Adamec, D., and R.W.Jr. Garwood, The simulated response of an upper-ocean density front to local atmospheric forcing (1985) J. Geophys. Res., 90(C1), 917-928. Uses the model from Adamec et al., 1981, which comes from Garwood, 77, a partially Ri dependent mixing model.

Haney, R.L., Midlatitude sea surface temperature anomalies: a numerical hindcast (1985) J. Phys. Ocean., 15, 787-799. Pacific region model. 12 depth levels above $200 \mathrm{~m}$. Surface mixing is done using a gradient Ri formulation, with critical value 0.25. Follows Adamec, 1981. Heat fluxes calculated from bulk formulae.

Price, J.F., R.A. Weller, and R. Pinkle, Diurnal cycling: observations and models of the upper ocean response to diurnal heating, cooling and wind mixing (1986) J. Geophys. Res., 91(C7), 8411-8427. The now-classic Ri model, with the innovation of the smoothing of the profiles at the base of the mixed layer using a Ri-gradient formulation, which gives a more realistic water column profile (see Martin P.J., 1986). Also includes high-resolution diurnal mixed layer current meter and CTD data taken using R/V FLIP.

Musgrave, D.L., J. Chou, and W.J. Jenkins, Application of a model of upper-ocean physics for studying seasonal cycles of oxygen (1989) J. Geophys. Res., in press, Integrates a Price et al. (1986) mixed layer model with a model for dissolved $\mathrm{O}_{2}$, to estimate that the $\mathrm{O}_{2}$ production rate is $3-4 \mathrm{~mol} / \mathrm{m}^{2} \mathrm{y}$ 


\section{A.3 Turbulence Closure Schemes}

Mellor, G.L., and T. Yamada, A hierarchy of turbulence closure models for planetary boundary layers (1974) J. Atmos. Sci., 31, 1791-1806. Explains the simplification scheme by which the levels $2,2.5,3$, and 4 models are derived.

Mellor, G.L., and P.A. Durbin, The structure and dynamics of the ocean surface mixed layer (1975) J. Phys. Ocean., 5, 718-728.

Klein, P., and M. Coantic, A numerical study of turbulent processes in the marine upper layers (1981) J. Phys. Ocean., 11, 849-863. They use Mellor's level 3 model. They find that deepening occurs as a result of current shear, rather than by the wind directly.

Mellor, G.L., and T. Yamada, Development of a turbulence closure model for geophysical fluid problems (1982) Rev. Geophys. Space Phys., 20(4), 851-875.

Deardorff, J.W., A multi-limit mixed layer entrainment formulation (1983) J. Phys. Ocean., 13, 988-1002.

Therry, G., and P. Lacarrere, Improving the eddy kinetic energy model for planetary boundary layer description (1983) Boundary-Layer Meteorology, 25, 63-88. Compared by Martin, P.J. to other types of mixed layer models. Very similar to Mellor's but formulated so that the Richardson number at which mixing occurs is slightly different than in the Mellor formulation.

Klein, P., and B. Coste, Effects of wind-stress variability on nutrient transport into the mixed layer (1984) Deep Sea Res., 31(1), 21-37. They use Mellor's level 2 model, and find that mixing occurs due to shear, rather than directly caused by the wind stress. They find that in a steady wind, nutrients mix up in pulses, rather than steadily.

Miyakoda, K., and A. Rosati, The variation of sea surface temperature in 1976 and 1977 2. The simulation with mixed layer models (1984) J. Geophys. Res., 89(C4), 6533-6542.

Rosati, A., and K. Miyakoda, A general circulation model for upper ocean simulation (1988) J. Phys. Ocean., 18, 1601-1626. Ocean general circulation model with particular focus on the upper ocean. Six gridpoints in the upper $70 \mathrm{~m}$, with mixing predicted using Mellor level 2.5 turbulence closure. The use of monthly mean wind speed data underestimates the evaporative heat flux, relative to predictions using $12-\mathrm{hr}$ average wind speed. 
Mellor, G.L. Retrospective on oceanic boundary layer modeling and second moment closure (1989) Manuscript in submission. Another summary of the physics, reflecting recent discussion in the field. 


\section{Appendix B. Annotated Bibliography of General Circulation Models}

\section{B.1 Models descended from Bryan and Cox (GFDL)}

Cox, M.D., A mathematical model of the Indian Ocean (1070) Deep Sea Res., 17, $47-$ 75. Surface temperature and salinity imposed from observations. They ran the model with increasing levels of horizontal resolution, with the final 1 deg., and with a $50 \mathrm{~m}$ deep mixed layer. The momentum mixing coefficient was 100 times greater between this box and the next one down.

Bryan, K., S. Manabe, and R.C. Pacanowski, A global ocean-atmospheric climate model. Part II. The oceanic circulation (1975) J. Phys. Ocean., 5, 1, 30-46. Does sea ice using heat fluxes, with no parameterization of leads. Doesn't allow ice movement with current if the ice is greater than $4 \mathrm{~m}$ thick. Uses a $\mathrm{U} *$ formulation for forced convection of the mixed layer; also includes convective mixing. The top box is at $25 \mathrm{~m}$, the next at $85 \mathrm{~m}$. The model was used in conjunction with an atmospheric model (Manabe et al., 75).

Bryan, K., and L.J. Lewis, A water mass model of the world ocean (1979) J. Geophys. Res., 84 (C5), 2503-2517. Temperature, salinity specified at the surface. Uses a KT mixed layer, along with convective mixing. Layers at $25,85 \mathrm{~m}$.

Bryan, K., Models of the world ocean (1979) Dyn. Atm. Oceans, 3, 327-338. A review of the field as of 1979.

Washington, W.M., A.J. Semtner, G.A. Meehl, D.J. Knight, and T.A. Mayer, A general circulation experiment with a coupled atmosphere, ocean, and sea ice model (1980) J. Phys. Ocean., 10, 1887-1908. Used by Meehl, 82. Four vertical layers, very coarse resolution $(5 \mathrm{deg})$. Monthly mean wind speeds; heat fluxes predicted. Sea ice model from Semtner (1976).

Bryan, K., Seasonal variation in meridional overturning and poleward heat transport in the Atlantic and Pacific Oceans: a model study (1982) J. Mar. Res., 40, suppl., 39-53. Uses the model described by Bryan and Lewis, 1979, which has imposed surface temperatures and salinities. Uses a bulk TKE budget KT-type wind mixing parameterization in the upper ocean. Depth levels at 25 and $85 \mathrm{~m}$. Designed to test the response of the lover ocean by specifying the upper ocean boundary conditions. 
Meehl, G.A., W.M. Washington, and A.J.Jr. Semtner, Experiments with a global ocean model driven by observed atmospheric forcing (1982) J. Phys. Ocean., 12, 301312. Explores the effect of seasonal forcing, using the model described by Washington et al., 1980. The model has a $50 \mathrm{~m}$ deep surface layer, and the next level is at $500 \mathrm{~m}$. Uses heat fluxes predicted using a simple parameterization, as well as monthly average wind stress. Surface salinity is imposed. Sea ice using the thermodynamic model of Semtner, 76.

Han, Y.J., A numerical world ocean general circulation model Part I. Basic design and barotropic experiment (1984) Dyn. Atm. Oceans, 8, 107-140. Mixed layer based on a bulk model. Sea ice uses the solid ice heat flux model from Semtner (1976). Heat, momentum fluxes predicted using transfer formulas.

Han, Y.J., A numerical world ocean general circulation model Part II. A baroclinic experiment (1984) Dyn. Atm. Oceans, 8, 141-172.

Adamec, D., and R.W.Jr. Garwood, The simulated response of an upper-ocean density front to local atmospheric forcing (1985) J. Geophys. Res., 90(C1), 917-928. Uses the model from Adamec et al. (1981), which comes from Garwood, (1977), a partially $\mathrm{Ri}$-dependent mixing model.

Haney, R.L., Midlatitude sea surface temperature anomalities: a numerical hindcast (1985) J. Phys. Ocean., 15, 787-799. Pacific region model. 12 depth levels above $200 \mathrm{~m}$. Surface mixing is done using a gradient $\mathrm{Ri}$ formulation, with critical value 0.25. Follows Adamec, 1981. Heat fluxes calculated from bulk formulae.

Schlesinger, M.E., W.L. Gates, and Y.J. Han. The role of the ocean in $\mathrm{CO}_{2}$ induced climate change: preliminary results from the OSU coupled atmosphere - ocean general circulation model (1985) in Coupled Ocean Atmosphere Models, edited by Nihoul, pp. 447-476. The ocean model of Han (1984) was used, coupled with an atmospheric circulation model, to determine that the e-folding time for ocean warming is on the order of 75 years. Was run for 16 years.

Sarmiento, J.L., On the North and tropical Atlantic heat balance (1986) J. Geophys. Res., 91 (C10), 11677-689. Uses Pacanowski and Philander surface mixing (shear dependent mixing coefficient). Six boxes in the upper $100 \mathrm{~m}$. Wind stress is predicted from monthly wind speed, but $T$ and $S$ are imposed at $5 \mathrm{~m}$ from observation.

Rosati, A., and K. Miyakoda, A general circulation model for upper ocean simulation (1988) J. Phys. Ocean., 18, 1601-1626. Ocean general circulation model with particular focus on the upper ocean. Six gridpoints in the upper $70 \mathrm{~m}$, with mixing predicted using Mellor level 2.5 turbulence closure. The use of monthly mean wind speed data underestimates the evaporative heat flux, relative to predictions using 12-hr average wind speed. 
Semtner, A.J., and R.M. Chervin, A simulation of the global ocear circulation with resolved eddies (1988) J. Geophys. Res., 93 (C12), 15522-22. Detailed upper ocean simulation to determine the effect of surface eddies on the meridional heat flux. Temperature, salinity constrained at the surface and below the thermocline at observed values. The top gridpoint was at $25 \mathrm{~m}$, with 10 boxes in the upper $750 \mathrm{~m}$.

Sarmiento, J.L., M.J.R. Fasham, U. Siegenthaler, R. Najjar, and J.R. Toggweiler, Models of chemical cycling in the oceans: progress report II (1989) Ocean Tracers Laboratory Technical Report \# 6, Uses the model of Toggweiler (1989). Also describes the nutrient-restoring model used to argue that DOC provides an "invisible" bioactive nitrogen pool.

Toggweiler, J.R., K. Dixon, and K. Bryan, Simulations of radiocarbon in a coarseresolution, world ocean model I: steady-state pre-bomb distributions (1989) J. Geophys. Res., 94 (C6), 8217-8242. 12 levels, $\sim 4$ deg horizontal resolution. Forced surface T,S. Vertical mixing in the thermocline influences the vertical profile of ${ }^{14} \mathrm{C}$; a value of $0.3 \mathrm{~cm}^{2} / \mathrm{s}$ is required.

Toggweiler, J.R., K. Dixon, and K. Bryan, Simulations of radiocarbon in a coarse resolution world ocean model II: distributions of bomb-produced 14C (1989) J. Geophys. Res., 94 (C6), 8243-8264. Uses the transient ${ }^{14} \mathrm{C}$ distributions as tracers to assess the accuracy of the circulation model. 


\section{B.2 The Model at the Max Plank Gesellschaft}

Maier-Reimer, E., Towards a global ocean carbon model (1984) Prog. Biometeorology, $3,295-310$. Focuses on the chemistry of $\mathrm{CO}_{2}$ in the circulation model.

Maier-Reimer, E., and K. Hasselmann, Transport and storage of $\mathrm{CO}_{2}$ in the ocean -- an inorganic ocean-circulation carbon cycle model (1987) Climate Dynamics, 2, 6390. The gridpoints are staggered, so that scalars were defined at 75 and $150 \mathrm{~m}$, and vectors at 112 and $200 \mathrm{~m}$. Free convection is included, but forced convection would be meaningless at this resolution; no embedded mixed layer. The velocity field from the model was "frozen" and used to circulate $\mathrm{CO}_{2}$ for these experiments.

Sausen, R., K. Barthel, and K. Hasselmann, Coupled ocean-atmosphere models with flux correction (1988) Climate Dyn., 2, 145-163. They address the problem of coupled atmosphere - ocean model "drift".

Bacastow, R., and E. Maier-Reimer, Circulation model of the ocean carbon cycle. Manuscript. Focuses mainly on the addition of carbon to the circulation model. The shallowest gridpoint is at 125 meters; no embedded mixed layer. Convective mixing is included. Specified temperature and salinity at the sea surface. 


\section{B.3 Other Models and Reviews}

Holland, W.R. The role of the upper ocean as a boundary layer in models of the oceanic general circulation (1977) in Modelling and Prediction of the Upper Layers of the Ocean, edited by E.B. Kraus, pp. 7-29.

Semtner, A.J.Jr., Development of efficient, dynamical ocean-atmosphere models for climate studies (1984) J. Climate and App. Met., 23, 3, 353-374.

Semtner, A.J.Jr. History and methodology of m'sdelling the circulation of the world ocean (1986) in Advanced Physical Orcanographic Modelling, edited by J.J. O'Brien, pp. 23-32. Good history of circulation models: relatively recent. Also has detailed description of timesteps, yrid sizes, diffusion coefficients, etc. 


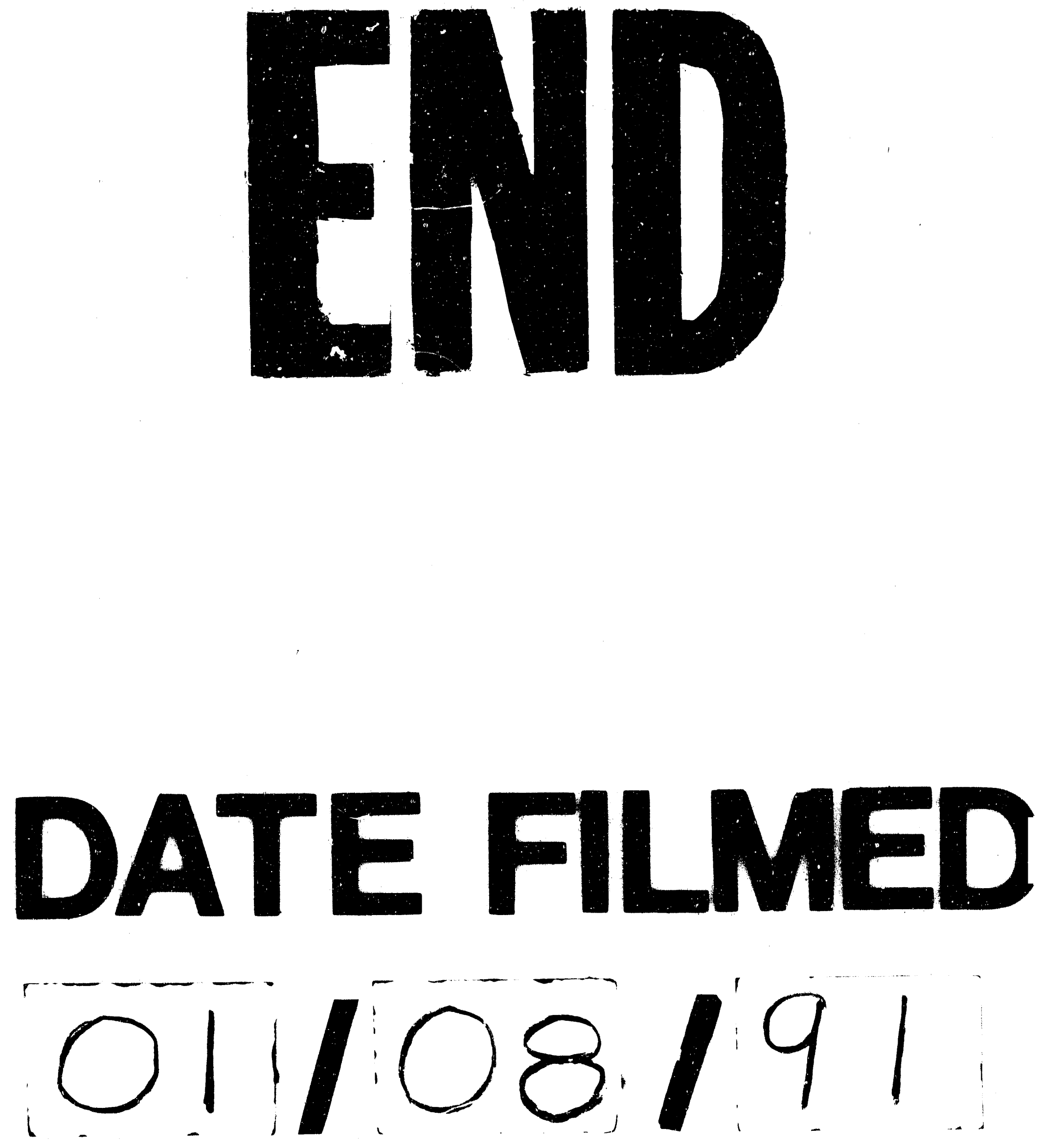
